\title{
Quantifying the impact of sub-grid surface wind variability on sea salt and dust emissions in CAM5
}

\author{
Kai Zhang ${ }^{1}$, Chun Zhao ${ }^{1}$, Hui Wan ${ }^{1}$, Yun Qian ${ }^{1}$, Richard C. Easter ${ }^{1}$, Steven J. Ghan ${ }^{1}$, Koichi Sakaguchi ${ }^{1}$, and \\ Xiaohong Liu ${ }^{2}$ \\ ${ }^{1}$ Pacific Northwest National Laboratory, Richland, WA, USA \\ ${ }^{2}$ Department of Atmospheric Science, University of Wyoming, Laramie, WY, USA
}

Correspondence to: Kai Zhang (kai.zhang@pnnl.gov)

Received: 13 July 2015 - Published in Geosci. Model Dev. Discuss.: 27 August 2015

Revised: 14 January 2016 - Accepted: 29 January 2016 - Published: 12 February 2016

\begin{abstract}
This paper evaluates the impact of sub-grid variability of surface wind on sea salt and dust emissions in the Community Atmosphere Model version 5 (CAM5). The basic strategy is to calculate emission fluxes multiple times, using different wind speed samples of a Weibull probability distribution derived from model-predicted grid-box mean quantities.

In order to derive the Weibull distribution, the sub-grid standard deviation of surface wind speed is estimated by taking into account four mechanisms: turbulence under neutral and stable conditions, dry convective eddies, moist convective eddies over the ocean, and air motions induced by mesoscale systems and fine-scale topography over land. The contributions of turbulence and dry convective eddy are parameterized using schemes from the literature. Wind variabilities caused by moist convective eddies and fine-scale topography are estimated using empirical relationships derived from an operational weather analysis data set at $15 \mathrm{~km}$ resolution. The estimated sub-grid standard deviations of surface wind speed agree well with reference results derived from 1 year of global weather analysis at $15 \mathrm{~km}$ resolution and from two regional model simulations with $3 \mathrm{~km}$ grid spacing.

The wind-distribution-based emission calculations are implemented in CAM5. In terms of computational cost, the increase in total simulation time turns out to be less than $3 \%$. Simulations at $2^{\circ}$ resolution indicate that sub-grid wind variability has relatively small impacts (about $7 \%$ increase) on the global annual mean emission of sea salt aerosols, but considerable influence on the emission of dust. Among the considered mechanisms, dry convective eddies and mesoscale flows associated with topography are major causes of dust
\end{abstract}

emission enhancement. With all the four mechanisms included and without additional adjustment of uncertain parameters in the model, the simulated global and annual mean dust emission increase by about $50 \%$ compared to the default model. By tuning the globally constant dust emission scale factor, the global annual mean dust emission, aerosol optical depth, and top-of-atmosphere radiative fluxes can be adjusted to the level of the default model, but the frequency distribution of dust emission changes, with more contribution from weaker wind events and less contribution from stronger wind events. In Africa and Asia, the overall frequencies of occurrence of dust emissions increase, and the seasonal variations are enhanced, while the geographical patterns of the emission frequency show little change.

\section{Introduction}

Atmospheric aerosols are important modulators of cloud formation processes and the energy budget of the climate system. The physical processes associated with aerosol sources and sinks are often nonlinear. In global and regional general circulation models (GCMs), the variabilities of meteorological fields at scales not resolved by the computational mesh have been found to have direct influences on aerosol formation as well as the subsequent microphysical changes and removal processes (Qian et al., 2010; Stevens and Pierce, 2013). Those sub-grid variabilities (SGVs) hence eventually affect the simulated aerosol direct and indirect forcing (e.g., Haywood et al., 1997; Ghan and Easter, 1998; Gustafson et al., 2011). 
Among the different species of aerosols, sea salt and dust contribute to a large fraction of the total aerosol burden in the atmosphere (Textor et al., 2006). Substantial discrepancies have been seen in the simulated emission fluxes of these two aerosol types in global aerosol model inter-comparison studies (Textor et al., 2006; Huneeus et al., 2011). Although different parameterization schemes are used in individual models, the near-surface wind speed is always a major factor that affects the emission of sea salt and dust. In most global aerosol models, the emission calculations are based on the grid-box mean near-surface wind speed, or the friction velocity derived from that mean speed, despite the fact that wind speed can have large spatial variabilities inside a typical GCM grid box (100-200 km across each edge). Due to the strongly nonlinear dependence of emission flux on wind speed, emission estimates made solely from GCM grid-box mean quantities can differ considerably from the grid-box average of fluxes estimated at a finer spatial scale (Westphal et al., 1988). It is therefore important to take into account sub-grid wind variabilities when calculating winddriven aerosol emissions in GCMs.

In terms of the physical mechanisms that cause variabilities of near-surface wind at spatial scales of about $100 \mathrm{~km}$ or less, earlier studies have shown that processes of scales less than $1 \mathrm{~km}$ can have large impacts on wind speed variability in the near-surface layer. For example, turbulence is a major contributor under neutral or stable conditions (Lumley and Panofsky, 1964). When the boundary layer is unstable, dry convective eddies also enhance the wind variability (Deardorff, 1970; Panofsky et al., 1977). Since dry convection events occur often in warm and arid areas (e.g., in deserts), they can strongly affect the emission of dust aerosols. Mesoscale atmospheric processes such as topographic gravity waves and moist convection are also important contributors to wind variability. Gusty winds can be generated by topographic gravity waves near mountain downslopes (Durran, 1990), or in thunderstorm outflows over land and ocean (Mahoney, 1988) where strong downdrafts (cold pools) occur in association with strong precipitation events (Zeng et al., 2002; Feng et al., 2015). Jabouille et al. (1996) showed that wind gusts generated by convective outflow can significantly enhance the surface heat fluxes.

Attempts have been made to quantify the wind variability resulting from the abovementioned mechanisms. For example, Panofsky et al. (1977) and Banta et al. (2006) estimated the turbulence induced sub-grid standard deviation of nearsurface wind speed as functions of the turbulent kinetic energy (TKE) or friction velocity $\left(u_{*}\right)$. Studies based on theoretical analysis and large-eddy model simulations showed that impact of dry convection can be linked to the convective velocity scale (e.g., Panofsky et al., 1977; Deardorff, 1970; Schumann, 1988) and estimated from the surface buoyancy flux and boundary layer height. Using a cloud-resolving model, Redelsperger et al. (2000) investigated the impact of deep convection and derived parameterizations based on precipitation rates or convective mass fluxes.

The sub-grid wind variability parameterizations have been used in the calculation of surface heat and moisture fluxes (Godfrey and Beljaars, 1991; Redelsperger et al., 2000; Zeng et al., 2002) and dust emission (Lunt and Valdes, 2002; Hourdin et al., 2015) at scales similar to sizes of GCM grid boxes. In these studies, wind variability was used to estimate the grid-box mean wind speed, and the mean speed was used to do a single calculation of the heat, moisture, or dust mass flux. For dust emission, considering that the dependency on wind speed is highly nonlinear, several studies have attempted to further remedy the accuracy issue by constructing a frequency distribution of the surface wind speed for the emission calculation. Different types of probability density functions (PDFs) were assumed in the dust modeling studies. For example, Marcella and Eltahir (2010) used Gaussian distribution and Cakmur et al. (2004) used double-Gaussian distribution.

In this work, we introduced a sub-grid treatment for the sea salt and dust emission calculation for the Community Atmospheric Model version 5 (CAM5). Like in Cakmur et al. (2004), the contribution of neutral/stable turbulence, dry convective eddies, and moist convective eddies are considered. In addition to these processes, the impact of wind variabilities induced by mesoscale systems and topographygenerated gravity waves over land is parameterized with an empirical method. In contrast to Cakmur et al. (2004) and Marcella and Eltahir (2010), the wind PDF is assumed to follow the Weibull distribution (Justus et al., 1979; Pavia and O'Brien, 1986; Monahan, 2006; Carta et al., 2009).

This paper presents materials to answer the following scientific questions for the CAM5 model:

1. How can we approximate the wind SGV using the gridbox mean physical quantities provided by an atmospheric GCM?

2. How large is the impact of sub-grid variability of surface wind speeds on the grid-box mean aerosol emission?

3. How does the estimated surface wind SGV affect the sea-salt and dust aerosol distributions?

In the remainder of the paper, we first introduce the CAM5 model and the formulation of its sea salt and dust emission parameterizations (Sect. 2). We then address the three science questions in Sects. 3-5. Each section starts with a description of the methodology and data, then proceeds to a discussion of the results. The conclusions are drawn in Sect. 6.

\section{Sea salt and dust emissions in CAM5}

The climate model used in this study is CAM5.3 - the atmosphere component of the Community Earth System Model (CESM) version 1.2.0 
(http://www.cesm.ucar.edu/models/cesm1.2/). This section introduces the basic features of the model configuration (Sect. 2.1), describes the sea salt and dust emission parameterizations (Sects. 2.3 and 2.4), and introduces the strategy for considering sub-grid wind variability in the emission calculations (Sect. 2.5).

\subsection{CAM5 overview}

In this study we use CAM5 with the finite-volume dynamical core (Lin, 2004) at $1.9^{\circ}$ lat $\times 2.5^{\circ}$ long horizontal resolution and with 30 vertical layers. The modal aerosol module (MAM3; Liu et al., 2012a) represents the tropospheric aerosol life cycle, including various emission and formation mechanisms, microphysical processes, and removal mechanisms. Six aerosol components are considered in the model, including sulfate, black carbon, primary and secondary organic aerosols, sea salt, and mineral dust. The emission fluxes of sea salt and dust are calculated interactively, while the emissions of other aerosol and precursor gas species are prescribed. The stratiform cloud microphysics in CAM5 is represented by a two-moment parameterization (Morrison and Gettelman, 2008; Gettelman et al., 2008). Aerosols can affect the formation and properties of stratiform clouds by acting as cloud condensation nuclei $(\mathrm{CCN})$ or ice nucleating particles. Deep convection and shallow convection are parameterized using the schemes of Zhang and McFarlane (1995) and Park and Bretherton (2009), respectively. Aerosols do not affect microphysics in convective clouds. Moist turbulence is represented by the parameterization of Bretherton and Park (2009). Shortwave and long-wave radiative transfer calculations are performed using RRTMG (Rapid Radiative Transfer Model for General Circulation Model applications, Iacono et al., 2008; Mlawer et al., 1997). Processes related to the mass and energy exchanges at the atmosphere-land interface are described by the Community Land Model version 4 (CLM4; Lawrence et al., 2011). Further details of the CAM5 and CLM4 model formulations can be found in Neale et al. (2010) and Oleson et al. (2010), respectively.

\subsection{Notation and terminology}

In this paper, the symbol $\bar{\psi}$ denotes the average of a generic variable $\psi$ over a GCM grid box, where $\psi$ can be either scalar or vector.

For the horizontal wind vector $\boldsymbol{v}$, we use the capital letter $U$ to denote its magnitude (i.e., the wind speed):

$U \equiv|\boldsymbol{v}| \equiv \sqrt{\boldsymbol{v} \cdot \boldsymbol{v}} \equiv \sqrt{u^{2}+v^{2}}$.

Since $U$ is a nonlinear function of $\boldsymbol{v}$, the grid-box average of wind speed $\bar{U}$ is larger than the magnitude of the resolved grid-box mean wind vector $|\overline{\boldsymbol{v}}|$, due to the existence of sub-grid wind variation. The estimation of $\bar{U}$ is addressed in Sect. 4 (Eq. 28). Another point to clarify is that through- out the paper, the term surface wind is used to refer to the horizontal wind at the lowest model level.

\subsection{Sea salt emission scheme}

The sea salt emission scheme in CAM5 is based on the work of Mårtensson et al. (2003). The emission flux $F$ $\left(\mathrm{kg} \mathrm{m}^{-2} \mathrm{~s}^{-1}\right)$ in the default model is calculated as

$F=\left[U_{10}(|\overline{\boldsymbol{v}}|)\right]^{3.41} A_{\mathrm{ocn}} E$,

where $U_{10}(|\overline{\boldsymbol{v}}|)$ is the $10 \mathrm{~m}$ wind speed diagnosed from $|\overline{\boldsymbol{v}}|$ without considering the sub-grid wind variability. $A_{\mathrm{ocn}}$ is the area fraction of open ocean in the grid box, and $E$ is a function of sea surface temperature and the assumed emission size distribution. The detailed expression of $E$ can be found in Supplement of Liu et al. (2012a).

\subsection{Dust emission scheme}

The parameterization of mineral dust aerosol emission in CAM5 is strongly tied to the land component CLM. CLM considers multiple land units (vegetated, glacier, wetland, lake, and urban) within a grid box, among which only surfaces of the vegetated type can emit dust. Using the Dust Entrainment and Deposition (DEAD) model of Zender et al. (2003), it is assumed that dust sources are located in arid or semi-arid marginally vegetated regions where strong winds can mobilize dust from the surface. The vegetated land unit in CLM is further categorized by plant functional type (PFT, e.g., tropical broadleaf deciduous tree, boreal needleleaf evergreen tree; cf. Table 2.1 in Oleson et al., 2010). The dust emission flux is first calculated for each PFT; ${ }^{1}$ then summed up using the area-weighting to give the grid-box average, i.e.,

$\bar{F}=\sum_{j} A_{j} F_{j}$.

For the $j$ th PFT of a grid-box, the vertical flux of dust mass emission (unit: $\mathrm{kg} \mathrm{m}^{-2} \mathrm{~s}^{-1}$ ) is calculated by

$F_{j}=T S \alpha f_{\mathrm{m}} Q_{\mathrm{s}_{j}}$.

Here $T$ is an adjustable tuning parameter, which is time and space invariant. The source erodibility factor $S$ and the sandblasting mass efficiency $\alpha$ are time invariant but dependent on geographical location. $f_{\mathrm{m}}$ is the fraction of grid cell area covered by exposed bare soil suitable for dust mobilization. The horizontally saltating mass flux $Q_{\mathrm{s}_{j}}$ is calculated

\footnotetext{
${ }^{1}$ It should be noted that the bare ground defined in the dust emission parameterization is different from the bare ground land surface type defined in CLM. In the dust emission parameterization, the bare ground fraction decreases linearly as the vegetation area index increases from zero to a prescribed threshold value (Zender et al., 2003). Therefore, even for PFTs that are not bare ground according to the CLM categorization, dust emission is still possible. Furthermore, dust emission is not considered over ice sheets, wetland areas, or lakes in CAM5/CLM4.
} 

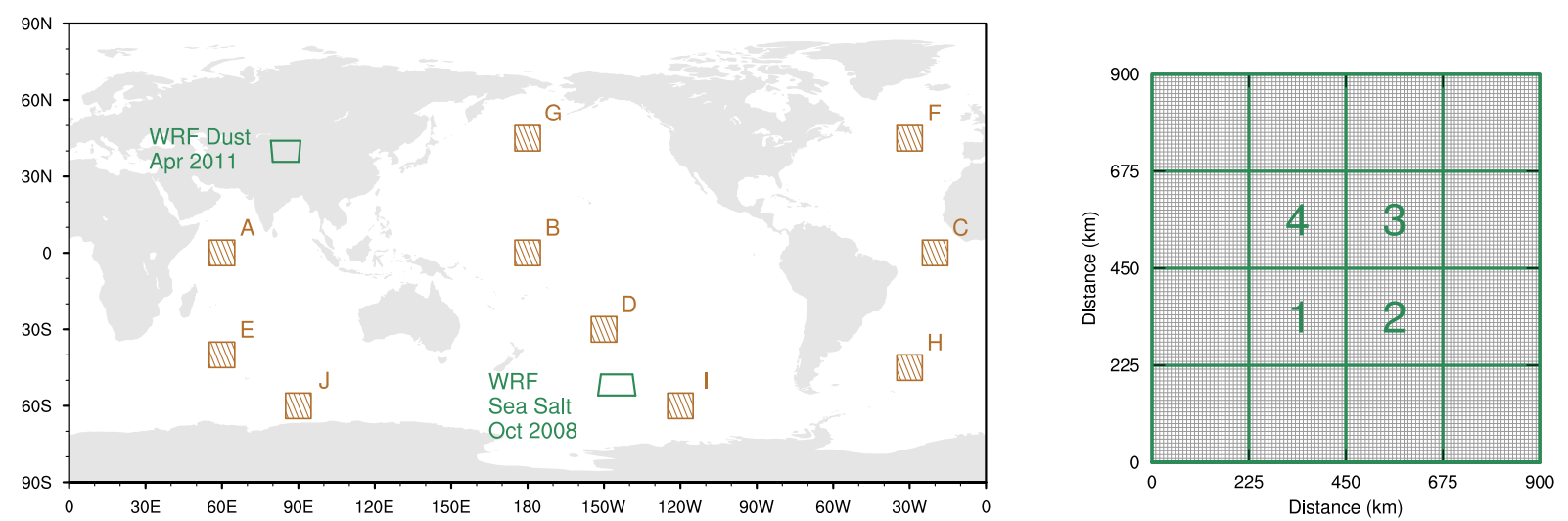

Figure 1. Left panel indicates the two $900 \mathrm{~km} \times 900 \mathrm{~km}$ WRF domains (green), and the ten $10^{\circ}$ lat $\times 10^{\circ}$ long regions (brown) in which the estimated sub-grid wind variabilities are evaluated in Fig. 8. Right panel shows the four imagined $225 \mathrm{~km}$ grid boxes (label as $1-4)$ in each of the WRF domains shown in the left panel. The $225 \mathrm{~km}$ grid boxes are used for the offline estimates in Figs. 4 and 6 , as well as the evaluations in Figs. 9 and 11.

according to White (1979). Note that there were typographical errors in the original Eq. (22) of White (1979), and in Eq. (10) of Zender et al. (2003). Our model uses the formula corrected by Namikas and Sherman (1997, Eq. 3 therein):

$Q_{\mathrm{s}_{j}}= \begin{cases}\frac{c_{\mathrm{s}} \rho_{\mathrm{a}} u_{* \mathrm{~s}_{j}}^{3}}{g}\left(1-\frac{u_{* \mathrm{t}}}{u_{* \mathrm{~s}_{j}}}\right)\left(1+\frac{u_{* \mathrm{t}}}{u_{* \mathrm{~s}_{j}}}\right)^{2}, & u_{* s_{j}}>u_{* \mathrm{t}} \\ 0, & u_{* \mathrm{~s}_{j}} \leqslant u_{* \mathrm{t}} .\end{cases}$

$c_{\mathrm{S}}$ denotes the saltation parameter (time-invariant and globally constant). $\rho_{\mathrm{a}}$ is air density, and $g$ is gravity. The threshold friction velocity $u_{* t}$ is determined by the size and density of the optimal saltation particles, which are assumed to have diameters of $75 \mu \mathrm{m}$ (Zender et al., 2003). $u_{* \mathrm{t}}$ also depends on soil moisture and ambient air density. The PFTdependent friction velocity $u_{* \mathrm{~s}_{j}}$ represents the Owen effect (Owen, 1964). In the default model (i.e., without wind SGV), it is calculated using

$u_{* \mathrm{~s}_{j}}= \begin{cases}u_{*_{j}}+0.003 U_{10_{j}}^{2}\left(1-\frac{u_{* \mathrm{t}}}{u_{*_{j}}}\right)^{2} & u_{*_{j}} \geqslant u_{* \mathrm{t}} \\ u_{*_{j}}, & u_{*_{j}}<u_{* \mathrm{t}} .\end{cases}$

The friction velocity $u_{*_{j}}$ and the $10 \mathrm{~m}$ wind speed $U_{10_{j}}$ are functions of surface wind speed, boundary layer stability, and characteristics of the land surface. Like in earlier studies (e.g., Godfrey and Beljaars, 1991; Lunt and Valdes, 2002), in order to take into account the enhancement of mean wind speed by dry convective eddies, in the default CAM5, the calculation of surface heat, moisture and tracer fluxes over land uses the following approximation for the grid-box mean surface wind speed:

$\bar{U}_{\text {adj }}=\sqrt{|\overline{\boldsymbol{v}}|^{2}+\sigma_{U, \mathrm{~d}}^{2}}$.

Here $\sigma_{U, \mathrm{~d}}$ is the standard deviation of sub-grid wind speed associated with dry convective eddy (details are given in
Sect. 4.2.2). $\bar{U}_{\text {adj }}$ is used in the calculation of $U_{10}$ and $u_{*}$, which not only affects Eq. (6) and hence the dust emissions, but also all other flux calculations that use $U_{10}$ and $u_{*}$ over land. On the other hand, the adjustment (Eq. 7) is not applied over the ocean; thus, it does not affect the sea salt emission in the default model.

\subsection{Incorporating surface wind variability in emissions calculations}

Equations (2)-(6) reveal that the parameterized sea salt and dust emissions are directly affected by the $10 \mathrm{~m}$ wind $U_{10}$ and the friction velocity $u_{*}$, both of which depend on the surface wind speed. In this study, the basic approach to introducing sub-grid-scale wind variability in the calculation of aerosol emissions is to

1. assume a Weibull PDF for surface wind speed, and calculate the Weibull PDF parameters from existing model quantities

2. obtain multiple samples of surface wind speed within each GCM grid box

3. calculate the sea salt and dust emissions for each sample

4. provide the average fluxes to the host GCM.

Using a generic notation, we assume $M$ samples of surface wind speed can be obtained in a GCM grid box (i.e., $U_{i}$ with $i=1, \cdots, M)$, each of which represents an area fraction $w_{i}$, and has a corresponding $10 \mathrm{~m}$ wind $U_{10_{i}}$ and a friction velocity $u_{*_{i}}$. The grid-box mean sea salt emission flux is then calculated by

$\bar{F}=A_{\mathrm{ocn}} E \sum_{i} w_{i} U_{10_{i}}^{3.41}$.

For dust, we note that the friction velocity $u_{*}$ is strongly affected by land surface characteristics, which has partially 

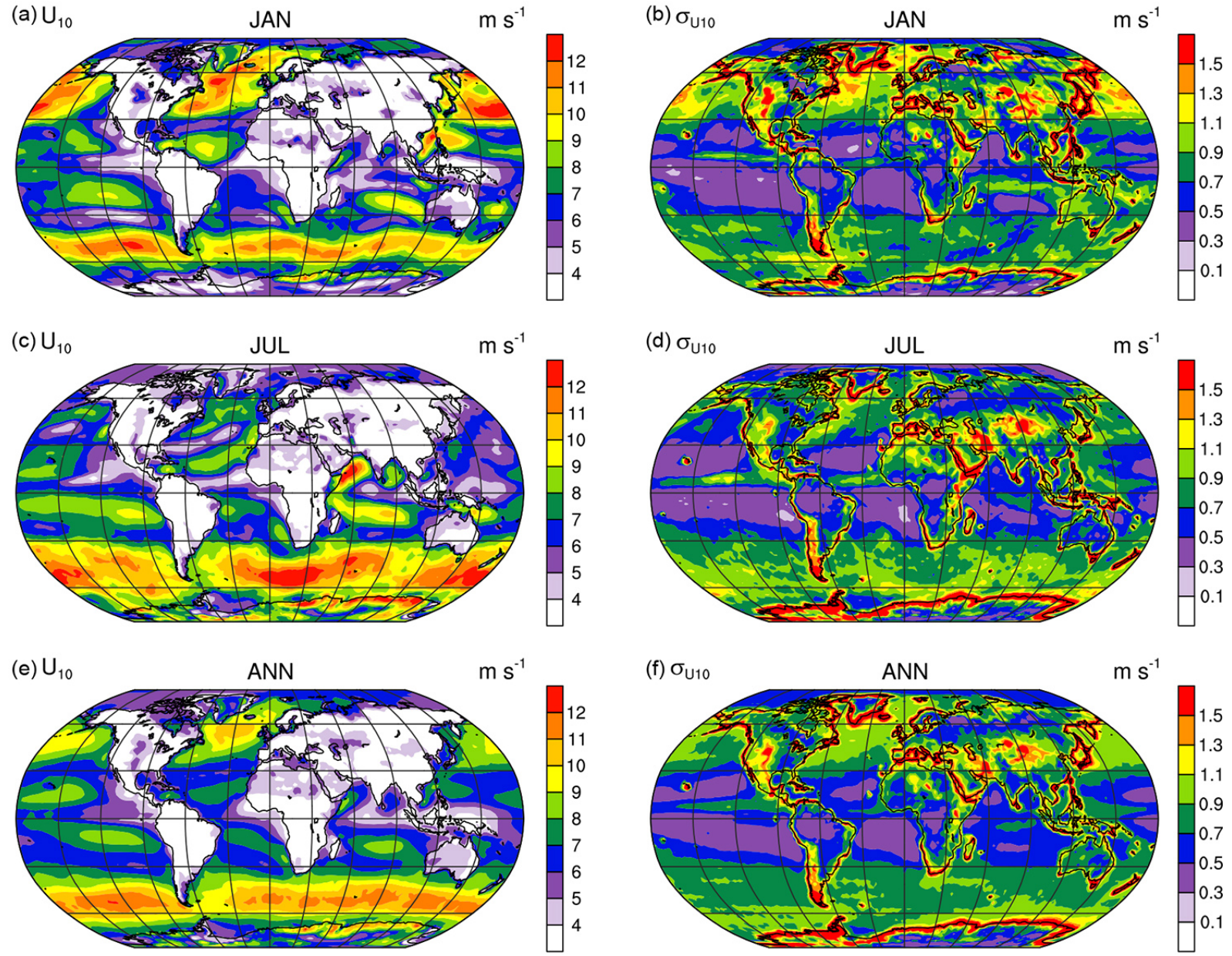

Figure 2. Grid-box average (left column) and sub-grid standard deviation (right column) of the $10 \mathrm{~m}$ wind speed, diagnosed on an imagined $2^{\circ} \times 2^{\circ}$ horizontal grid from the ECMWF $15 \mathrm{~km}$ global analysis of the year 2011 . From top to bottom: January average, July average, and annual mean. See Sect. 3 for further details.

been taken into account (in the default model) by distinguishing different PFTs. This is different from the dust emission parameterization used in many other global aerosol-climate models (e.g., ECHAM5-HAM2 described in Zhang et al., 2012), in which the calculation of the friction velocity often neglects the impact of sub-grid variation of vegetation type. On the other hand, for a single PFT in a grid cell, $u_{*}$ can still have strong SGV because of the inhomogeneity in surface wind speed. In this study we take multiple surface wind samples $\left(U_{i}, i=1, \cdots, M\right)$ for each PFT, calculate $u_{* \mathrm{~s}_{j, i}}$ and $Q_{\mathrm{s}_{j, i}}$ in analogy to Eqs. (6) and (5), respectively, then calculate the grid-box mean dust emission flux as a weighted sum over all PFTs and all surface wind samples, i.e.,

$\bar{F}=\sum_{j} A_{j}\left(\sum_{i} w_{j, i} F_{j, i}\right)$.

The strategy of doing multiple emission calculations in each grid box is similar to that used by Grini and Zender (2004) and Cakmur et al. (2004), although in our work the wind speed samples are derived differently. The details are explained in Sects. 4 and 5. Before describing the method for estimating sub-grid wind variability, we first present in the next section a diagnostic analysis of the impact of sub-grid wind on aerosol emission, assuming that the sub-grid wind variability is already known.

\section{Offline estimate of the impact of wind variability on emissions}

This section addresses the first science question listed in Sect. 1, assuming that the sub-grid variability of surface wind is known to sufficiently high accuracy. Applying a method similar to those used in many recent studies on resolution sensitivities of parameterized physical processes (e.g., Arakawa et al., 2011), we use high-resolution wind data and derive the surface wind statistics in imagined grid boxes that are roughly $200 \mathrm{~km}$ by $200 \mathrm{~km}$ in size. 

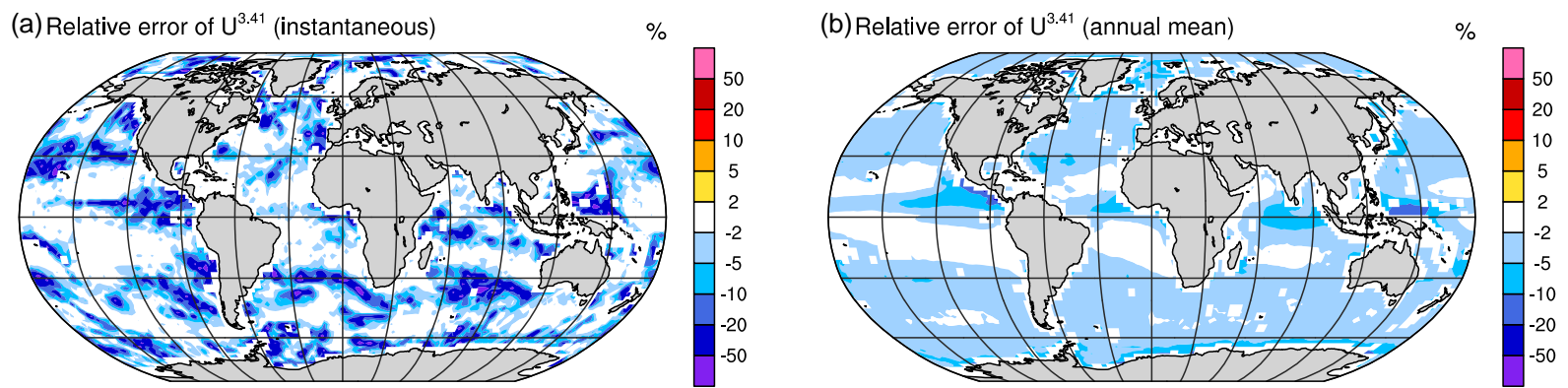

Figure 3. Relative error of $U_{10}^{3.41}$ over the ocean, caused by ignoring sub-grid wind variability. The quantity shown is the relative error of Eq. (10) with respect to Eq. (11), calculated on an imagined $2^{\circ} \times 2^{\circ}$ horizontal grid using the ECMWF $15 \mathrm{~km}$ global analysis. Left panel shows the instantaneous results at an arbitrarily chosen time (00:00 GMT on 1 January 2011). Right panel shows the relative error of the year 2011 annual mean.
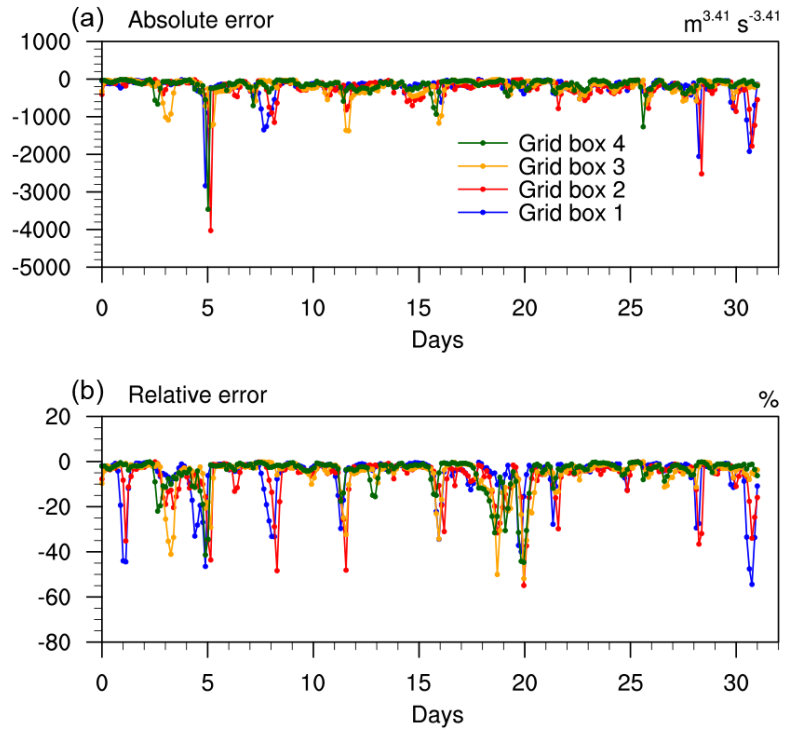

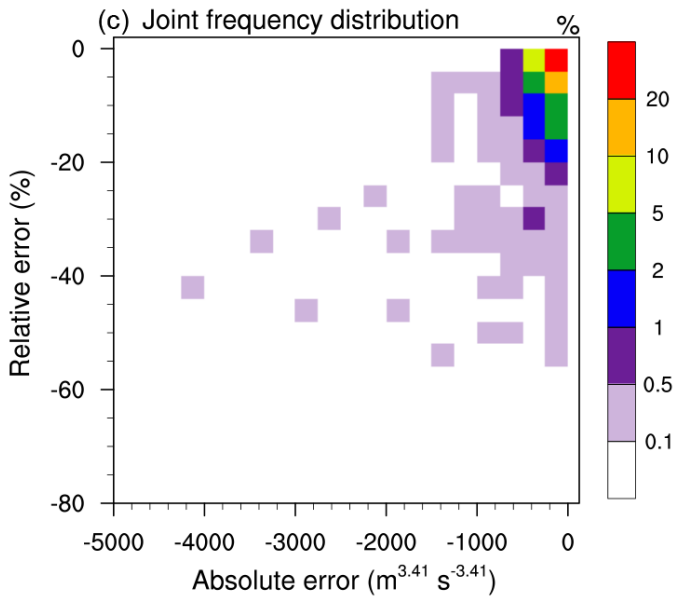

Figure 4. (a-b) Time series of the error of $U_{10}^{3.41}$ in the four $225 \mathrm{~km} \times 225 \mathrm{~km}$ grid boxes in the WRF domain over the Southern Ocean (cf. Fig. 1 and Sect. 3). The absolute and relative errors are calculated for Eq. (10) assuming Eq. (11) is the "truth". (c) Joint frequency distribution of the relative and absolute errors. All the four time series shown in panels (a) and (b) are considered as one sample for the calculation.

Two sources of high-resolution data are used. The first data set contains 1 year (2011) of the 6-hourly operational analysis from the European Center for Medium-range Weather Forecasts (ECMWF). The horizontal resolution is $T_{L} 1279$, corresponding to grid spacings of about $15 \mathrm{~km}$. A special advantage of this data set is its global coverage, which is important for estimating the impact of wind SGV on sea salt emission. Our imagined coarse-resolution grid is a $2^{\circ}$ lat $\times 2^{\circ}$ long mesh. Each grid box overlaps about 200 points on the $T_{L} 1279$ grid. The averaging from fineresolution grid points to coarse-resolution boxes uses an area weighting that takes into account fractional contributions of the ECMWF grid cells in each $2^{\circ}$ imagined grid box.

The second wind data set includes two regional model simulations conducted with the WRF (Weather Research and Forecasting) model v3.4.1 (Skamarock and Klemp,
2008) at $3 \mathrm{~km}$ resolution: one for October 2008 with a $900 \mathrm{~km} \times 900 \mathrm{~km}$ domain centered at $52^{\circ} \mathrm{S}, 145^{\circ} \mathrm{W}$ over the Southern Ocean, and one for 1-7 April 2011 with a $900 \mathrm{~km} \times 900 \mathrm{~km}$ domain centered at $40^{\circ} \mathrm{N}, 85^{\circ} \mathrm{E}$ over western China near the Taklamakan Desert (Fig. 1). Both simulations used the CAM5 physics suite implemented in WRF by Ma et al. (2014). The meteorological initial conditions and lateral boundary conditions are derived from ECMWF analysis at $6 \mathrm{~h}$ intervals. For the calculations discussed in this section and in Sect. 4, each WRF domain is divided into 16 imagined grid boxes of $225 \mathrm{~km}$ spacing, and only the four inner boxes are used in order to avoid potential impacts of boundary effects on the regional model simulations (Fig. 1b).

A global view of the sub-grid spatial variability of surface wind is presented in Fig. 2, which shows the grid-box mean 
(a) Relative error of $U^{\wedge} 3$ (instantaneous)

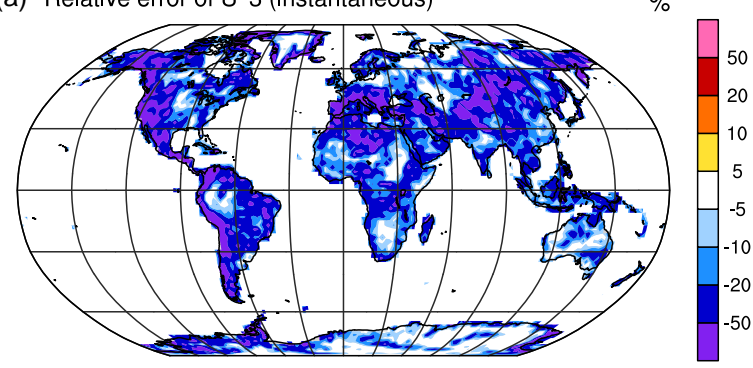

(b) Relative error of $U^{\wedge} 3$ (annual mean)

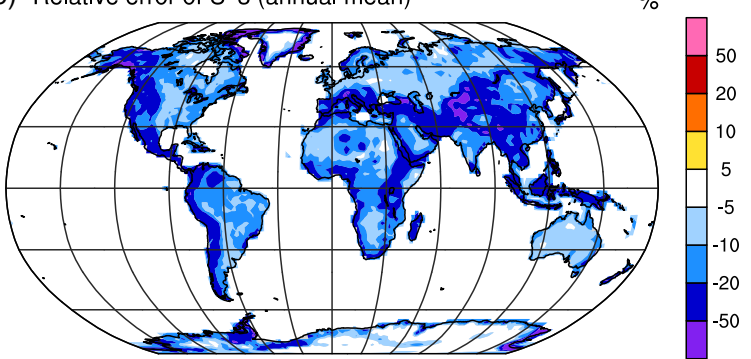

Figure 5. As in Fig. 3 but for the relative errors of $U_{10}^{3}$ over land. The errors are calculated for Eq. (12) assuming Eq. (13) is the truth.

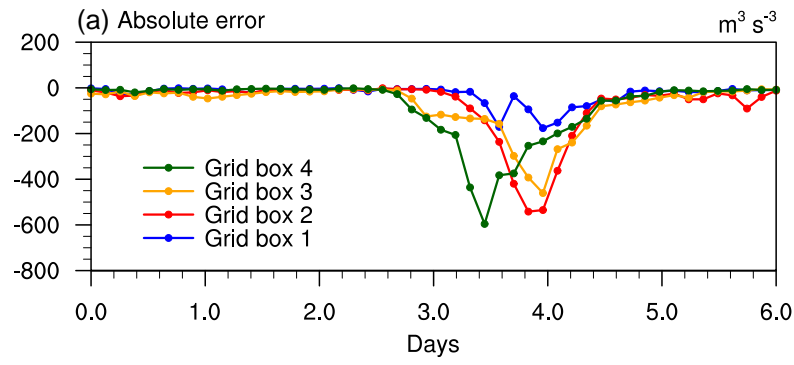

(b) Relative error

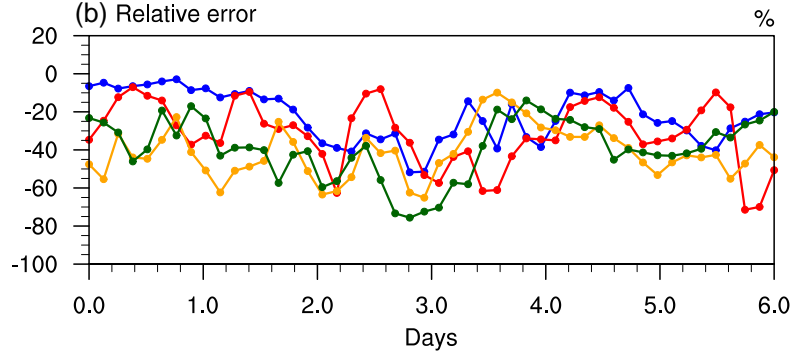

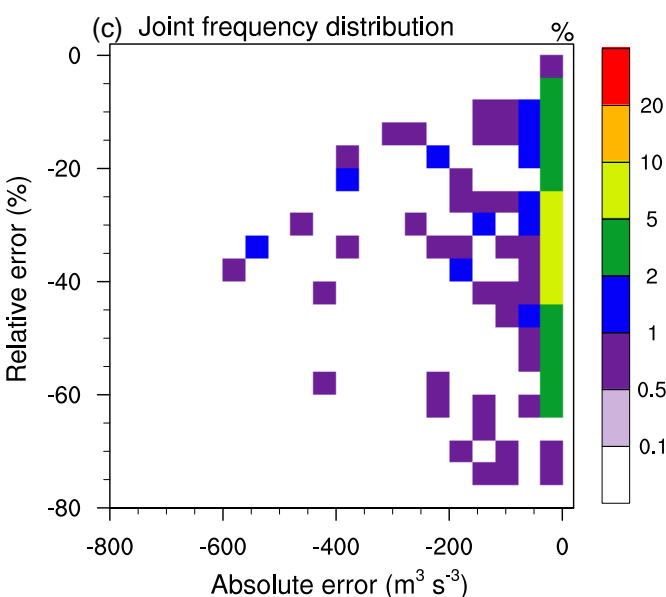

Figure 6. As in Fig. 4 but for the WRF simulation over western China, and for the error of $U_{10}^{3}$. The errors are calculated for Eq. (12) assuming Eq. (13) is the truth.

and sub-grid standard deviation of $U_{10}$ on the $2^{\circ}$ coarse mesh. The statistics were first calculated from the $15 \mathrm{~km}$ ECMWF data at 6-hourly intervals, then temporally averaged to give the January, July, and annual averages. Over the ocean, gridbox mean wind and sub-grid variability are both strong in the storm tracks. In contrast, the trade wind regions have relatively strong winds but weak SGV, while the regions with strong tropical precipitation are associated with weak gridbox mean wind and strong spatial variability. Over land the mean wind is generally low, but there is strong spatial inhomogeneity associated with complex topography (e.g., mountains and coastlines). The contrasts in geographical distribution between the grid-box mean and sub-grid variability indicate that the mean wind alone is not a good predictor of variability.

Based on Eq. (8), the impact of sub-grid wind variability on the parameterized sea salt emission can be estimated by comparing the following two quantities for each grid box:

$U_{\mathrm{m}}^{3.41}=\bar{U}_{10}^{3.41}$
$U_{\mathrm{r}}^{3.41}=\sum_{i} w_{i} U_{10_{i}}^{3.41}$

The subscripts " $\mathrm{m}$ " (for mean) and " $\mathrm{r}$ " (for reference) denote the quantities calculated without and with the consideration of sub-grid wind variability, respectively. The relative differences diagnosed from the ECMWF data are shown for an arbitrarily chosen time instance in Fig. 3a, and for the annual mean in Fig. 3b. For about $75 \%$ of the ocean grid points, the relative difference is small (less than $-10 \%$ in magnitude). On the other hand, local differences exceeding $-30 \%$ in magnitude cover about $8 \%$ of the ocean area. The largest spatial variances are mainly associated with precipitation events driven by convective activities.

A similar comparison is presented using the WRF simulation over the Southern Ocean. In Fig. 4a-b, results are shown for the four $225 \mathrm{~km}$ grid boxes located at the center of the WRF domain, presented as time series for the entire simulation period (October 2008). In Fig. 4c, the joint frequency distribution of the relative and absolute errors are shown, with all four grid boxes considered together. Although the 
grid spacing of the WRF simulation is a factor of 5 smaller than that of the ECMWF analysis, the relative differences between $U_{\mathrm{m}}^{3.41}$ and $U_{\mathrm{r}}^{3.41}$ are similar: most of the time, $U_{10}^{3.41}$ calculated from the grid-box mean wind speed agrees within $5 \%$ with the reference result $\left(U_{\mathrm{r}}^{3.41}\right)$; there are events occurring every 3-5 days during which the relative discrepancies can increase to -30 to $-50 \%$, but the absolute differences are generally small.

To get an estimate of the impact of sub-grid wind variability on dust emission, we start from Eq. (5) and assume there is only one PFT in each coarse-resolution grid box. Since the dominant term (in terms of sub-grid variability) in the formula is $u_{*}^{3}$, and $u_{*}$ is closely related to the $10 \mathrm{~m}$ wind $U_{10}$, we further simplify the analysis by comparing

$U_{\mathrm{m}}^{3}=\bar{U}_{10}^{3}$,

$U_{\mathrm{r}}^{3}=\sum_{i} w_{i} U_{10_{i}}^{3}$.

It should be pointed out that unlike the actual parameterization in the model, this simplified comparison does not take into account the dependence of emission flux on the threshold friction velocity. As can be derived from Eq. (5), the omission will lead to an underestimation of the emission flux and emission error when $u_{* \mathrm{~s}}>1.6 u_{* \mathrm{t}}$, and an overestimation when $u_{* \mathrm{~s}}$ is close to or smaller than $u_{* \mathrm{t}}$. The purpose of using the simplified formulae here is to give a first, rough estimate of the impact of wind SGV. More accurate comparisons using the CAM5 model with the Zender et al. (2003) parameterization are presented in Sect. 5.

Figures 5 and 6 present the emission errors caused by using the grid-box mean wind speed, diagnosed according to the simplified Eqs. (12) and (13) using the ECMWF analysis and the WRF simulation. The relative differences are typically between -10 and $-50 \%$ in western China, central Asia, and western United States, which are important dust source regions (Fig. 5). The WRF simulation in western China contains a strong-wind event around day 4, during which the relative differences between $U_{\mathrm{m}}^{3}$ and $U_{\mathrm{r}}^{3}$ increase to -20 to $-50 \%$. The frequency distributions shown in Figs. 4 and 6 indicate that large absolute errors occur considerably more often for dust emission than for sea salt emission.

The results shown above suggest that considering only the grid-box mean wind speed can lead to substantial inaccuracies on the parameterized aerosol emission, especially for dust. For a more accurate estimate of the impact of surface wind SGV on aerosol emissions and climatology in CAM5, it is worth implementing multiple emission calculations using different wind samples. In the next section, we present and evaluate a method that derives wind speed samples using GCM-predicted mean states.
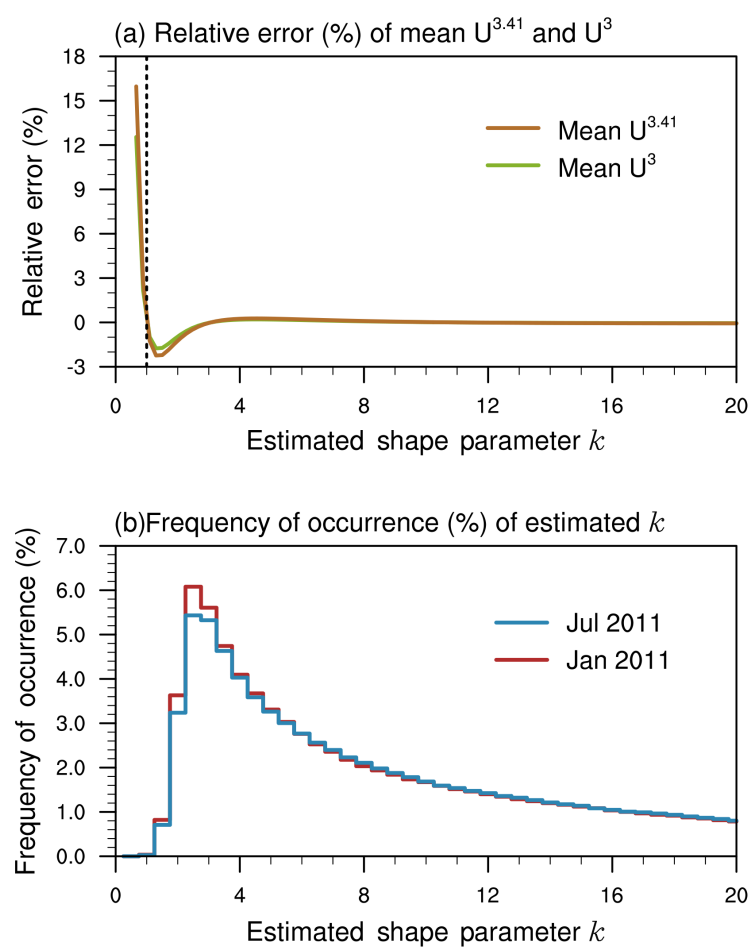

Figure 7. (a) Relative error in $\overline{U_{10}^{3.41}}$ and $\overline{U_{10}^{3}}$ as a result of estimating the shape and scale parameters of a Weibull distribution using Eqs. (15) and (16). (b) Histograms of the Weibull shape parameter $k$ estimated with Eq. (15) using 6-hourly ECMWF analysis of January and July 2011 for imagined $2^{\circ}$ grid boxes. Further details can be found in Sect. 4.1.

\section{Approximating sub-grid wind variability}

Earlier studies have shown that the Weibull distribution is useful and appropriate for representing the temporal frequency distribution of wind speed, for example for wind energy applications (Justus et al., 1978). Ridley et al. (2013) showed that if the sub-grid variance inside a GCM grid box is known, using the Weibull PDF to represent the sub-grid variability of surface wind speed can help improve the accuracy of the emission calculation compared to a simulation that does not account for the SGV. In this section we discuss empirical methods to estimate the sub-grid wind distribution using GCM-predicted physical quantities.

\subsection{Weibull distribution}

Assuming the wind speed $U$ is a random variable, the PDF of a Weibull distribution can be written as

$p(U ; k, c)=\left(\frac{k}{c}\right)\left(\frac{U}{c}\right)^{k-1} e^{-(U / c)^{k}}$

where $k$ is the shape parameter and $c$ the scale parameter. $k$ and $c$ can be derived from the mean $(\bar{U})$ and the standard 
deviation $\left(\sigma_{U}\right)$ using method 3 of Justus et al. (1978), i.e.,

$k=\left(\frac{\bar{U}}{\sigma_{U}}\right)^{1.086}$,

$c=\frac{\bar{U}}{\Gamma(1+1 / k)}$,

where $\Gamma$ is the Gamma function.

We note that $k$ and $c$ computed from Eqs. (15) and (16) are approximations, which define a new Weibull distribution that features exactly the same mean $\bar{U}$ but differs from the original distribution in terms of higher moments. To evaluate the impact of the parameter estimation error on our study of aerosol emission, we generated a large number of Weibull distributions with the true shape and scale parameters varied in the range $(0,20)$. Figure 7 a shows the relative error of $\overline{U_{10}^{3.41}}$ and $\overline{U_{10}^{3}}$ corresponding to the estimated Weibull parameters. The reference values were derived from the original Weibull distributions with known (i.e., true) $k$ and $c$. The relative errors are independent of the scale parameter $c$; thus, only relationships to the shape parameter are presented here. (The relative errors are plotted against the estimated $k$, rather than the known true value, to allow for straightforward comparison with Fig. 7b; see below.) Figure 7 a shows that the relative errors in $\overline{U_{10}^{3.41}}$ and $\overline{U_{10}^{3}}$ are both small (within $3 \%$ ) when the estimated shape parameter is larger than 1. The errors are negligible when $k>3$ (corresponding to negative skewness or very small positive skewness). For $k<1$, Eqs. (15) and (16) give much less accurate results, but this is expected to have negligible impact on our results presented later in this paper, because as Fig. $7 \mathrm{~b}$ indicates, the shape parameters of $2^{\circ}$ grid boxes derived from the ECMWF analysis rarely drop below 1 . The two histograms in Fig. 7b were calculated from 6-hourly global data of January and July 2011. The percentages of grid boxes with $k<1$ were $0.036 \%$ in January and $0.025 \%$ in July.

The usefulness of the Weibull distribution for representing the sub-grid wind variability can be seen in a diagnostic comparison similar to those shown in Figs. 3 and 5. Using the $15 \mathrm{~km}$ ECMWF data, we derive the grid-box mean and sub-grid standard deviation of the $10 \mathrm{~m}$ wind speed $\left(\bar{U}_{10}\right.$ and $\sigma_{U_{10}}$, respectively) on the $2^{\circ}$ coarse mesh, and calculate the shape and scale parameters $k$ and $c$ using Eqs. (15) and (16). The central $99 \%$ of the resulting Weibull PDF is then divided into 100 bins. The discrete PDFs are used in Eqs. (11) and (13), with $w_{i}$ being the frequency of occurrence of bin $i$.

The errors in $\overline{U_{10}^{3.41}}$ and $\overline{U_{10}^{3}}$ caused by using the Weibull distribution instead of the true sub-grid wind distribution (not necessarily Weibull) turn out to be very small (not shown). In terms of both instantaneous values and annual averages, the use of Weibull distribution typically gives errors of less than $2 \%$ over the ocean and less than $5 \%$ over land. These errors are substantially smaller than in the case when only the gridbox mean values are included in the calculation (Figs. 3 and
5 in the previous section). This suggests that with sufficiently accurate estimates of the parameters, the Weibull distribution is a very good approximation of the spatial variability of the near-surface wind speed.

Fitting the Weibull distribution as discussed above requires the sub-grid mean and standard deviation of wind speed. Typically, a GCM provides only the grid-box mean wind vector $\overline{\boldsymbol{v}}$. The magnitude of that mean wind vector, $|\overline{\boldsymbol{v}}|$, is an underestimate of $\bar{U}$, while a better approximation can be obtained using the standard deviation $\sigma_{U}$. Obtaining $\sigma_{U}$ is thus a key step for fitting the sub-grid wind speed distribution. Considering that the SGV is caused by parameterized physical processes and sub-grid-scale features such as complex topography, the ideal sources of information on $\sigma_{U}$ would be the corresponding parameterizations. For example, the representation of cold pool in the unified convection scheme (UNICON; Park, 2014) might be used to estimate the SGV caused by mesoscale organized flow associated with deep convection. A high-order turbulence scheme might provide useful predictions of the Raynold's stress to help estimate the wind variability related to turbulence. Since these are not yet available in the standard version of CAM5, we resort to empirical estimates of $\sigma_{U}$ as discussed next.

\subsection{Empirical estimate of $\sigma_{U}$}

Relatively simple methods have been used in the literature to estimate the parameters needed to determine a Weibull distribution for wind speed. For example, Grini and Zender (2004) and Capps and Zender (2008) used method 5 of Justus et al. (1978), i.e.,

$k=C \sqrt{\bar{U}}$

with $C$ being a constant. In the work of Grini and Zender (2004), $C$ was set to 0.94 to approximate the sub-grid wind variability on land. Their formula effectively estimates $\sigma_{U}$ from $\bar{U}$ using

$\sigma_{U}=1.059 \bar{U}^{0.54}$.

Some other studies on dust emission used an even simpler method by assuming $k$ is constant over land (e.g., Menut, 2008)

In this work we are interested in global emissions of sea salt and dust. Preliminary investigations indicated that constant $k$ or Eq. (17) with constant $C$ gave reasonable results over certain locations over land but had large regional discrepancies, and both methods were unsatisfactory over the ocean. Below we use a set of empirical formulae to relate $\sigma_{U}$ to four types of physical processes:

i. neutral/stable turbulent mixing $\left(\sigma_{U, \mathrm{t}}\right)$

ii. dry convective eddy $\left(\sigma_{U, \mathrm{~d}}\right)$

iii moist convective eddy over the ocean $\left(\sigma_{U, \mathrm{~m}}\right)$ 
iv. mesoscale flow associated with sub-grid orography over land $\left(\sigma_{U, 1}\right)$.

The total sub-grid standard deviation of surface wind speed is defined as

$\sigma_{U}=\sqrt{\sigma_{U, \mathrm{t}}^{2}+\sigma_{U, \mathrm{~d}}^{2}+\sigma_{U, \mathrm{~m}}^{2}+\sigma_{U, 1}^{2}}$

Among those processes, the first two are associated with spatial scales that can only be resolved by large-eddy simulations (LESs) or Direct Numerical Simulations (DNSs). Such simulations, and the related observational data, are still very limited in terms of spatial and temporal coverage (e.g., Dipankar, 2015). We do not have sufficient amount of new, high-resolution data to analyze these processes or evaluate parameterizations. We thus choose to use results from earlier studies in the literature.

Moist convective eddies and orography-related mesoscale flows are partially resolved in the ECMWF $15 \mathrm{~km}$ analysis. Since the analysis is available for 2 years (2011 and 2012), we use the first year to derive empirical relationships for estimating $\sigma_{U, \mathrm{~m}}$ and $\sigma_{U, 1}$, then use the second year to evaluate the fitting. The accuracies of the derived relationships are inherently constrained by the resolution of the analysis data. The fact that the $15 \mathrm{~km}$ resolution is too coarse to resolve neutral/stable turbulence and dry convective eddies is an advantage for us, in that the sub-grid wind variability estimated from the ECMWF analysis do not include the impact of neutral/stable turbulence and dry convective eddies. There is hence no double counting between $\sigma_{U, \mathrm{~m}}$ and $\sigma_{U, 1}$ derived from the $15 \mathrm{~km}$ analysis, and the $\sigma_{U, \mathrm{t}}$ and $\sigma_{U, \mathrm{~d}}$ estimated using process-based formulation. One might still raise the concern that the $15 \mathrm{~km}$ resolution is also too coarse to fully resolve moist convection and fine-scale topography effect. Although the concern is legitimate, we show in the section that the derived relationships are able to give quite accurate emission estimates when evaluated against the WRF simulations ( $3 \mathrm{~km}$ resolution). This provides good confidence in the empirically fitted relationships, at least for important regions of sea salt and dust emission that are of interest for our purposes. In the future, it will be useful to further evaluate and update the sub-grid wind variability parameterizations using additional high-resolution data (when they become available). Another useful and challenging research topic is to construct process-based parameterizations instead of empirical fitting as discussed here.

\subsubsection{Neutral/stable turbulent mixing}

To consider the influence of turbulent mixing in a neutral or stable boundary layer, we follow ECMWF (2004) and estimate the resulting wind variability using

$\sigma_{U, \mathrm{t}}= \begin{cases}2.29 u_{*}(|\overline{\boldsymbol{v}}|) & \text { when } F_{\theta_{\mathrm{v}}} \leqslant 0 \\ 0 & \text { when } F_{\theta_{\mathrm{v}}}>0\end{cases}$
Here $F_{\theta_{v}}$ is the surface buoyancy flux (unit: $\mathrm{m}^{2} \mathrm{~s}^{-1}$ ) defined in Zeng et al. (2002), $\theta_{\mathrm{v}}$ is the virtual potential temperature (unit: $\mathrm{K}), u_{*}(|\overline{\boldsymbol{v}}|)$ is the friction velocity diagnosed from the speed of the grid-box mean wind $|\overline{\boldsymbol{v}}|$. In Eq. (20) the strength of turbulence is represented by the friction velocity $u_{*}$, not the TKE (cf., e.g., Cakmur et al., 2004). This choice results from the experience that TKE is not provided by all GCMs, and, when available, its characteristic value and spatio-temporal distribution can differ substantially from model to model.

\subsubsection{Dry convective eddies}

The contribution of dry convective eddies to sub-grid wind variability is estimated using a formulation recommended by Redelsperger et al. (2000) and Lunt and Valdes (2002):

$\sigma_{U, \mathrm{~d}}= \begin{cases}0 & \text { when } F_{\theta_{\mathrm{v}}} \leqslant 0 \\ \left(\frac{g H F_{\theta_{\mathrm{v}}}}{\theta_{\mathrm{v}}}\right)^{\frac{1}{3}} & \text { when } F_{\theta_{\mathrm{v}}}>0,\end{cases}$

$H$ is the boundary layer height (unit: $\mathrm{m}$ ), and $g$ is gravity.

Note that by using the surface buoyancy flux $F_{\theta_{\mathrm{v}}}$ as a criterion, we consider contributions from either neutral/stable turbulence mixing (Eq. 20) or dry convective eddies (Eq. 21), but not both, for the purpose of avoiding double counting.

\subsubsection{Moist convective eddies over the ocean $\left(\sigma_{U, \mathrm{~m}}\right)$}

For the influence of moist convective eddies and downdrafts, Redelsperger et al. (2000) constructed an empirical formula based on two 2-D cloud-resolving model (CRM) simulations that covered 1 week in time and $512 \mathrm{~km}$ across the horizontal domain, with a horizontal resolution of $2 \mathrm{~km}$. Their formula uses the surface precipitation rate $P\left(\mathrm{mmday}^{-1}\right)$ as the predictor for sub-grid wind variability:

$\sigma_{U, \mathrm{~m}}=\ln \left(1+6.69 P-0.47 P^{2}\right)$.

In this study we are interested in sea salt emissions, the main sources of which are located in the storm tracks (i.e., mid-latitudes). Given that the Redelsperger et al. (2000) equation was derived from simulations of tropical deep convection with very limited temporal and spatial coverage, it was unclear whether the same relationship would be appropriate for our purpose. We attempted to derive a similar relationship using the ECMWF $15 \mathrm{~km}$ analysis of 2011 , and indeed found it difficult to obtain one good formula for all latitudes. The best-fit formula for a $2^{\circ} \times 2^{\circ} \mathrm{GCM}$ grid has the form

$\sigma_{U, \mathrm{~m}}= \begin{cases}0.95 \ln \left(1+4.01 \sqrt{P}+0.31 P^{2}\right) & \text { (ocean) } \\ 0 & \text { (land), }\end{cases}$

where

$P= \begin{cases}P_{\text {strat+conv }} & \text { where SST }<295 \mathrm{~K}, \\ 0.2 P_{\text {strat }+ \text { conv }} & \text { where SST } \geqslant 295 \mathrm{~K} .\end{cases}$ 


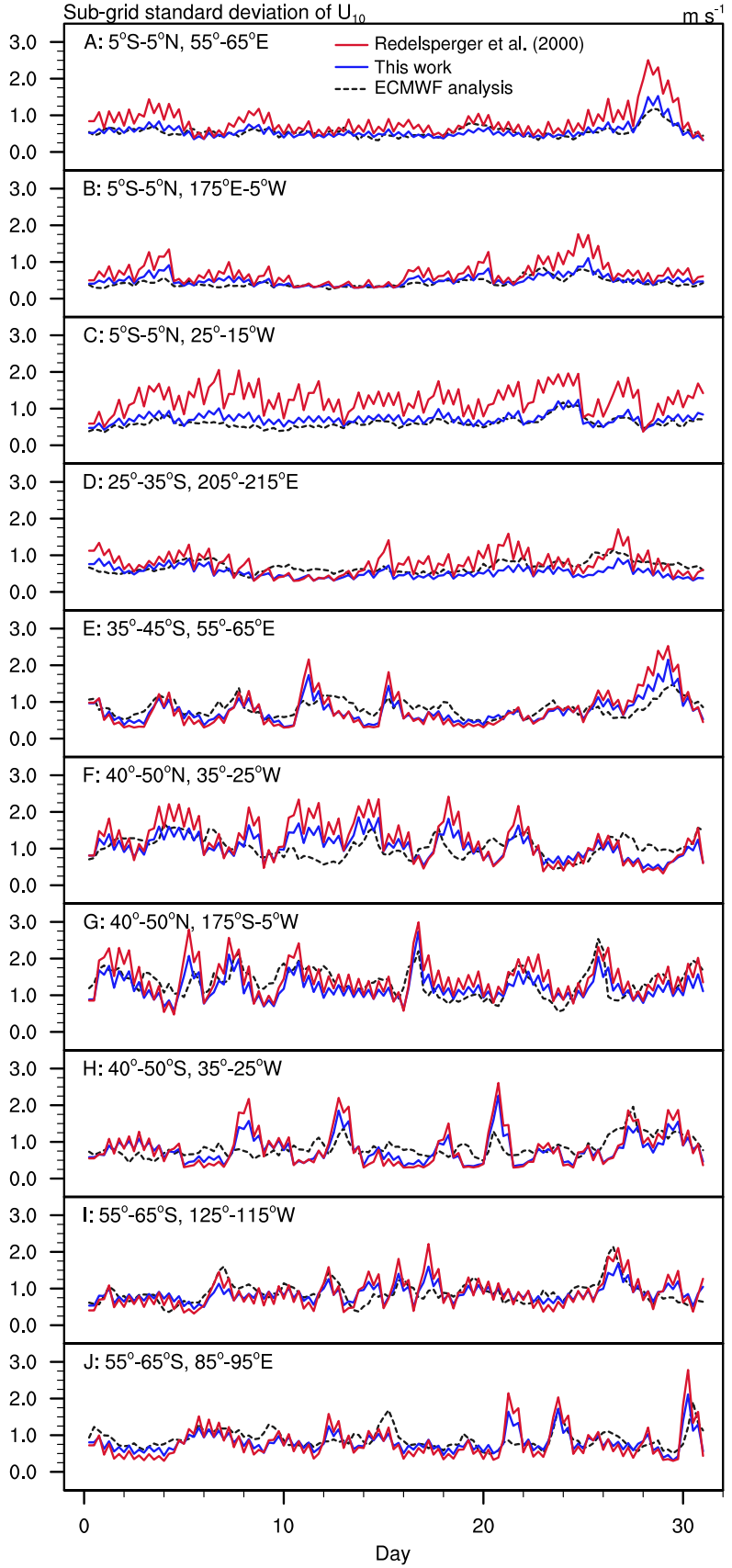

Figure 8. Time series of the sub-grid standard deviation of $U_{10}$ $\left(\mathrm{m} \mathrm{s}^{-1}\right)$ in January 2012 averaged over the $10^{\circ} \times 10^{\circ}$ hatched boxes in Fig. 1. Dashed black curves are directly diagnosed from the ECMWF surface wind data. Solid blue and red curves are the $\sigma_{U, \mathrm{~m}}$ calculated using the ECMWF precipitation rates and the empirical formulas of this study (Eq. 23) and Redelsperger et al. (2000) (Eq. 22), respectively.

The SST criterion essentially distinguishes the tropics and mid-latitudes.

Figure 8 presents time series of the sub-grid standard deviation of surface wind speed calculated with Eqs. (22) and

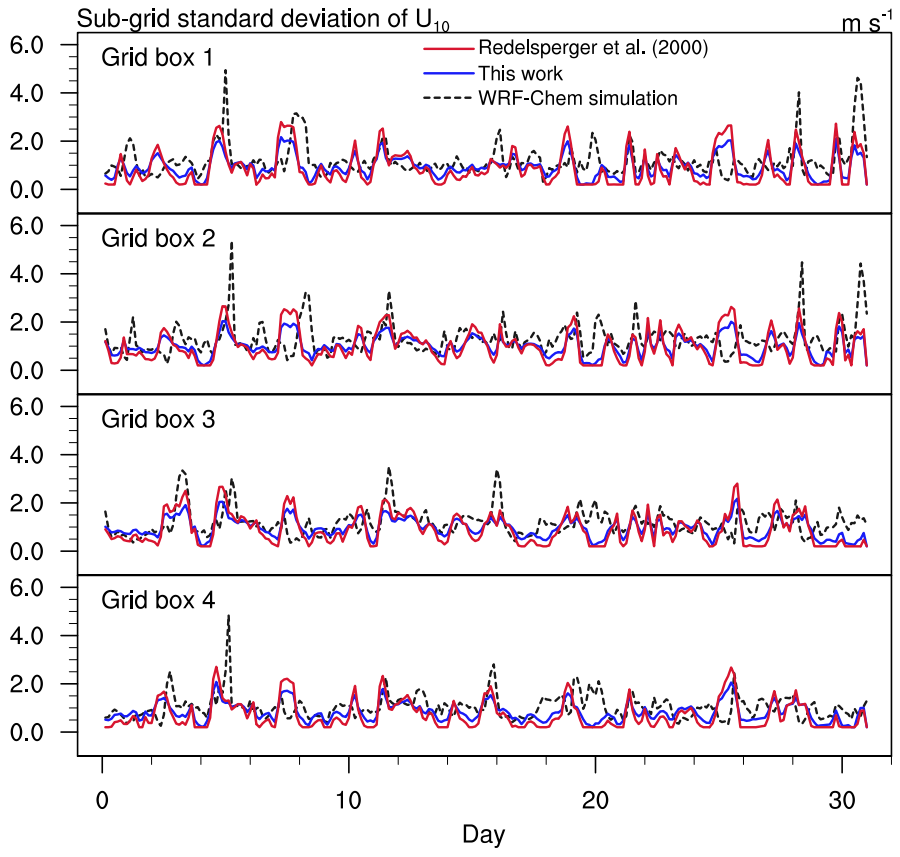

Figure 9. As in Fig. 8 but evaluating Eqs. (23) and (22) using the WRF simulation over the Southern Ocean. The domain of the WRF simulation and the location of the four imagined $225 \mathrm{~km} \times 225 \mathrm{~km}$ grid cells are illustrated in Fig. 1.

(23), and the values directly derived from the ECMWF analysis. The results are shown for January 2012 for a few arbitrarily chosen $10^{\circ} \times 10^{\circ}$ regions (cf. Fig. 1). Results in other months are similar and thus not shown. In the low latitudes, the Redelsperger et al. (2000) formula predicts considerably higher wind variability than both our fitting and the ECMWF analysis. This is consistent with our expectations since the CRM simulations, which the Redelsperger et al. (2000) is based on are capable of resolving substantially more convective activity than the ECMWF analysis. In the mid-latitudes, however, the two formulae give very similar estimates, and both agree reasonably well with the ECMWF analysis.

Given the $15 \mathrm{~km}$ resolution, one might still question whether the ECMWF analysis is an appropriate reference for the evaluation here. To address this issue, Fig. 9 evaluates the two empirical formulae by comparing the estimates with the WRF simulation over the Southern Ocean. For each of the $225 \mathrm{~km} \times 225 \mathrm{~km}$ box at the center of the WRF domain, the diagnosed sub-grid variability is shown in black and the estimated values in red and blue. Again, the two empirical formulae give very similar results. Both are able to capture the mean wind variability over the simulated period, and the most frequently occurring high and low values, although the strongest peaks are underestimated. The Redelsperger et al. (2000) formula gives larger peak values than our fitting derived from the ECMWF data, but the differences are relatively small. On the whole, the two empirical formulae have similar predictive skills. This provides confidence that they 


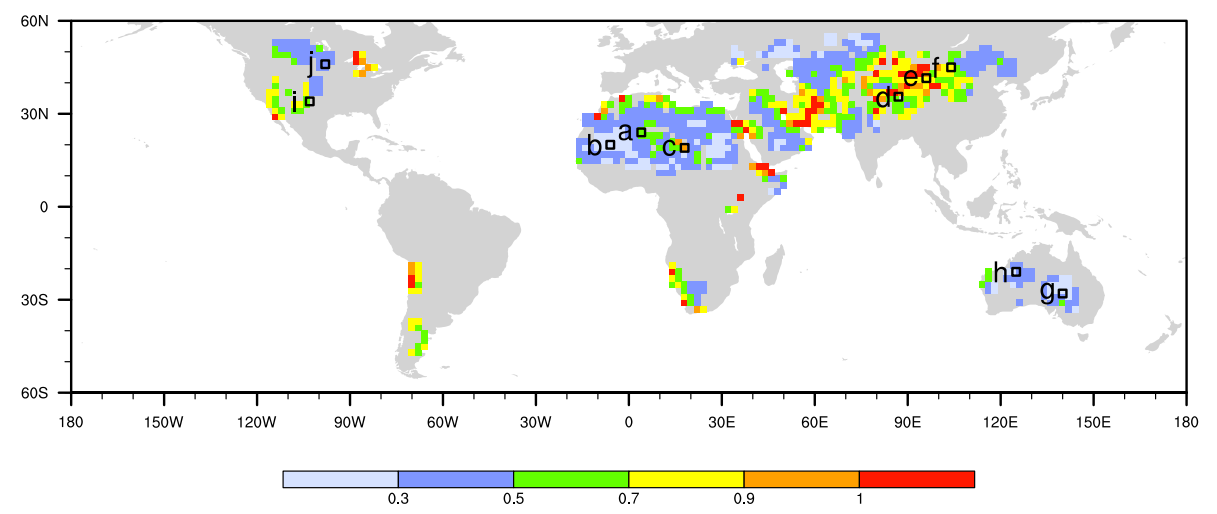

Figure 10. Geographical distribution of the coefficient $D$ (unitless) derived for a $2^{\circ}$ lat $\times 2^{\circ}$ long GCM grid using the ECMWF $15 \mathrm{~km}$ analysis of the year 2011 and Eq. (26). The locations with no results are either covered by land ice or lake, or associated with leaf area indices (LAI) larger than 0.3 throughout the year; thus, cannot have dust emission according to the parameterization of Zender et al. (2003) and the land surface characteristics data used in the CAM5 simulations in this paper. The black boxes correspond to the panels in Fig. 11 in which time series of sub-grid wind variability are analyzed.

are both suitable for estimating sub-grid wind variability in mid-latitudes. In principle one could also conduct and analyze a high-resolution WRF simulation of deep convection to get more insight into the discrepancies in the tropics between our fitting and the Redelsperger et al. (2000) formula. Such a comparison is not included in this paper because as discussed later in Sect. 5.3, CAM5 simulations indicate that sea salt emission fluxes are very low in the tropics; even with Redelsperger's formula, which gives stronger wind variability than our fitting does, the absolute increases in sea salt emission and loading remain negligible when compared with higher latitudes.

\subsubsection{Mesoscale flows over land $\left(\sigma_{U, 1}\right)$}

The sub-grid wind speed variance diagnosed from the ECMWF analysis (Fig. 2 in Sect. 3) indicates clearly that over land, the strongest variabilities are associated with complex topography. Such disturbances can be caused by pure dynamical effects, but they can also involve moist processes (e.g., cumulus convection), and thus are difficult to parameterize. A preliminary investigation showed that for individual locations, the sub-grid wind variance is strongly correlated with the grid-box mean wind speed. We therefore follow the idea of Eq. (17) but, unlike earlier studies in the literature, make the coefficient a location-dependent and time-invariant parameter. Also, in order to have a coefficient that scales with the SGV, we use the reciprocal of the coefficient $C$ (i.e., $D=1 / C)$ in the equations and figures below, i.e.,

$k(x, y, t)=\frac{\sqrt{\bar{U}(x, y, t)}}{D(x, y)}$,

where $x$ and $y$ denote longitude and latitude, respectively. The parameter $D$ is derived from the ECMWF analysis using the following procedure: first, for each $2^{\circ}$ grid cell, calculate the grid-box mean wind speed and the sub-grid standard deviation; second, calculate $k$ using Eq. (15); third, derive the time-invariant $C$ using temporally averaged $\bar{U}$ and $k$, i.e.,

$D(x, y)=\frac{\sum_{t=1}^{n} \sqrt{\bar{U}(x, y, t)}}{\sum_{t=1}^{n} k(x, y, t)}$.

The time index $t$ goes through all 6-hourly samples of the year 2011. After determining $D$, the standard deviation of sub-grid wind speed is calculated by

$\sigma_{U, 1}= \begin{cases}0 & \text { (ocean) } \\ \left(D|\overline{\boldsymbol{v}}|^{0.586}\right)^{1 / 1.086} & \text { (land). }\end{cases}$

In Fig. 10, the coefficient $D$ derived from the 2011 ECMWF analysis is shown in potential dust source regions. The spatial pattern of $D$ is strongly correlated with topography. As a result, $D$ shows substantial regional variation: Asia and South America have large areas with $D>0.5$, while most grid cells in Australia and North Africa have $D<0.5$. Within these regions, the coefficient also has substantial spatial variation at the thousand-kilometer scale.

Since larger values of $D$ correspond to stronger sub-grid wind speed variance (Eq. 27), the spatial variations in Fig. 10 suggest that using a global constant can lead to large regional biases. This is confirmed by Fig. 11, which evaluates surface wind SGV estimated by Eqs. (26) and (27) with fixed or spatially varying $D$, against SGV derived from the ECMWF data. In the case of fixed $D$, the constant value of $D=1.06$ ( $C=0.94$ ) comes from method 4 of Justus et al. (1978), and has been used by Grini and Zender (2004) and Capps and Zender (2008). Time series of the sub-grid standard deviation of surface wind speed in January 2012 are shown for ten $2^{\circ}$ grid boxes in North Africa (Fig. 11a-c), East Asia 

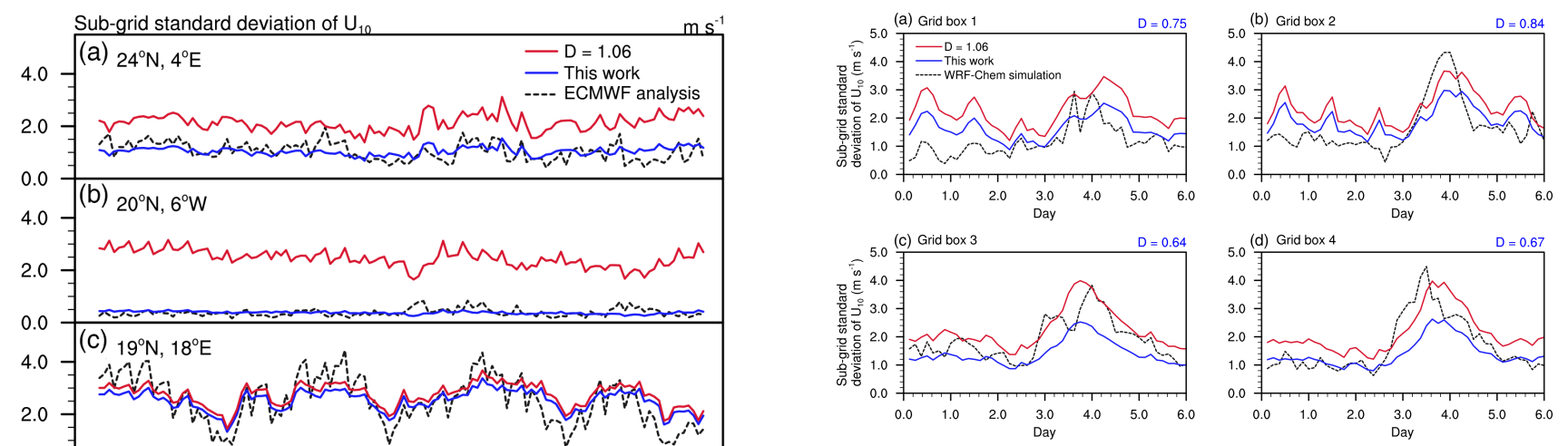

Figure 12. As in Fig. 11, but for the four $225 \mathrm{~km}$ boxes at the center of the WRF domain near the Taklamakan Desert. The $D$ values used for the blue curves are derived from the ECMWF analysis of year 2011 for $2^{\circ}$ lat $\times 2^{\circ}$ long grid cells that are closest to the $225 \mathrm{~km}$ boxes.

estimated with $D=1.06$ is about $100-200 \%$ larger than the analysis in Australia, and more than a factor of 3 stronger in northwest Africa, where the topography is relatively flat.

It is also worth noting that for our empirical estimates shown in Fig. 11, the coefficient $D$ is derived from the analysis of 2011 but applied to the year 2012. The agreement between the empirical estimate and the analysis suggests that the relationship between grid-box mean wind speed and subgrid wind variance is not strongly affected by interannual variability of the general circulation.

In Fig. 12, estimates of sub-grid wind speed variability based on constant or locally fitted $D$ are evaluated using the 7-day WRF simulation near the Taklamakan Desert. The black curves in the figure indicate wind variability in the four $225 \mathrm{~km} \times 225 \mathrm{~km}$ boxes at the center of the WRF domain (cf. Fig. 1), derived from the $3 \mathrm{~km}$ model output. The red curves are the estimates based on $D=1.06$. The results shown in blue are calculated using the $D$ values fitted from the ECMWF analysis for the $2^{\circ}$ lat $\times 2^{\circ}$ long grid cells that are closest to the $225 \mathrm{~km}$ boxes. Although the ECMWF analysis does not resolve scales smaller than $15 \mathrm{~km}$, the coefficient $D$ derived from the ECMWF data leads to very reasonable estimates of wind variability compared to the $3 \mathrm{~km}$ WRF simulation, providing confidence in the ECMWF analysis and the fitted $D$ values in regions of fine-scale topographical features. It should be mentioned that the reference wind data used here have limitations in terms of the spatial and temporal coverage, and the horizontal and vertical resolutions. Physical mechanisms of wind variabilities and dust emission in the real world and their representation in numerical models are highly complex. For example, Marsham et al. (2011) showed that models with parameterized or resolved convection can give different timings of summer dust uplift in West Africa. The parameterization of wind SGV presented in this paper is very simple and empirical. Process-based rep- 


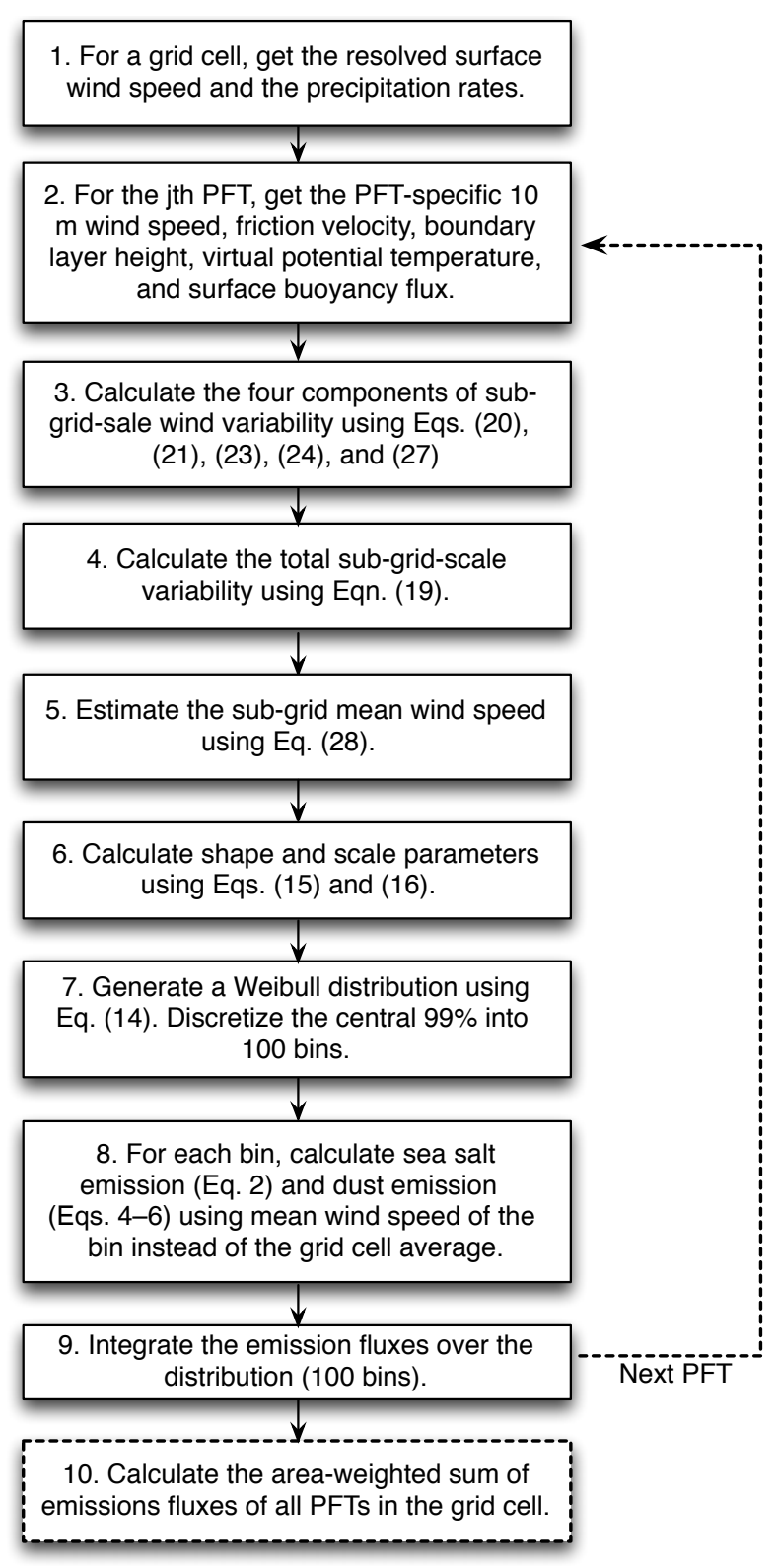

Figure 13. Flowchart illustrating the implementation of winddistribution-based sub-grid emission calculations in CAM5. Dashed lines indicate steps that are only relevant for the dust emission calculation.

resentation of different dust emission mechanisms is a topic for future study.

\subsection{Implementation in CAM5}

The wind-distribution-based emission calculations are implemented in CAM5, as illustrated in Fig. 13.

In the previous subsections we have shown that the Eqs. (23), (24), (26), and (27) can provide very good estimates of the sub-grid wind speed variability when compared with the ECMWF analysis and WRF simulations. These em- pirical relationships are combined with Eqs. (20) and (21) to provide an estimate of the total sub-grid variance of surface wind speed $\sigma_{U}$ using Eq. (19).

Given the GCM predicted grid-box mean wind vector $\overline{\boldsymbol{v}}$ and the estimated $\sigma_{U}$, we assume that the sub-grid mean wind speed can be approximated by

$\bar{U} \approx \sqrt{|\overline{\boldsymbol{v}}|^{2}+\sigma_{U}^{2}}$.

This is similar to Eq. (7), which originated from Zeng et al. (2002), but takes into account additional sources of wind speed SGV.

$\bar{U}$ and $\sigma_{U}$ are used in Eqs. (14)-(16) to determine a Weibull distribution. Surface wind speed samples $U_{j}$ are obtained by equally dividing the central $99 \%$ of the Weibull PDF into 100 bins. Sensitivity simulations with a 20 bin Weibull PDF show similar results. From the surface wind speed samples, the corresponding values of $10 \mathrm{~m}$ wind speed and friction velocity are derived, and used to calculate the grid-box mean sea salt and dust emission fluxes following Sect. 2.5. If the estimated $\sigma_{U}$ is smaller than $0.1 \mathrm{~m} \mathrm{~s}^{-1}$, we skip the derivation of Weibull PDF and wind samples, and use only the mean wind speed for the emission calculations. The computation cost for the sub-grid treatment is small (less than $3 \%$ of the total simulation cost).

The next section presents a series of CAM5 simulations to quantify the impact of sub-grid wind variability on aerosol emission and the model's mean climate. For clarification, we note that the $\sigma_{U}$ and $\bar{U}$ (Eq. 28) described above are applied only to the sea salt and dust emission parameterizations. As mentioned at the end of Sect. 2.4, the default model uses an adjusted mean wind speed (Eq. 7) for all calculations related to surface fluxes and boundary layer processes over land. This is unchanged in our simulations except for dust emission. We chose not to modify Eq. (7), so as to cleanly separate the impact of sub-grid variability on aerosol emission from the impacts on other physical processes.

\section{Impact on aerosol climatology in CAM5}

CAM5 simulations have been conducted for the year 2006 after a 3-month spin-up (October-December 2005). The horizontal winds were nudged to the ERA-Interim reanalysis with a relaxation timescale of $6 \mathrm{~h}$. Temperature and humidity were not nudged, since earlier experiences have shown that directly constraining these two fields might lead to substantially different model climate (Zhang et al., 2014; Jeuken et al., 1996). Details of the nudging implementation are described in Zhang et al. (2014). Nudging effectively constrains the large-scale circulation and suppresses the noise caused by natural variability, thus allowing for detection of changes in the simulated aerosol characteristics and their climate effects with substantially shorter simulations (see, e.g., Kooperman et al., 2012). 
(a) $\sigma_{U}$ (total)

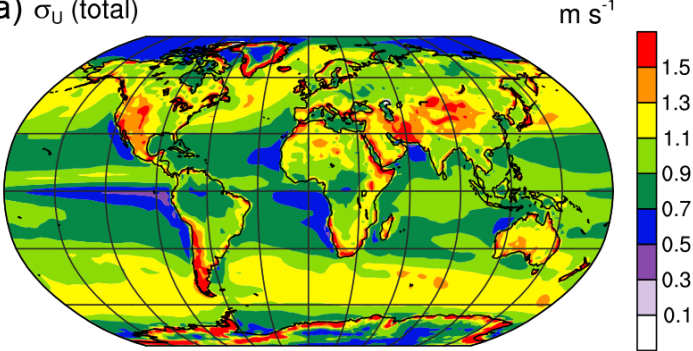

(c) $\sigma_{\mathrm{u}, \mathrm{d}}$
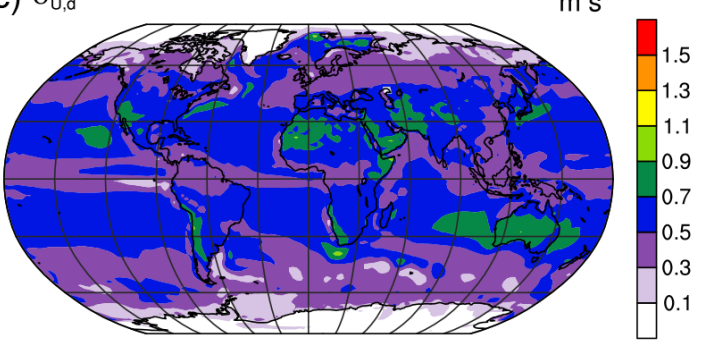

(b) $\sigma_{\mathrm{U}, \mathrm{t}}$

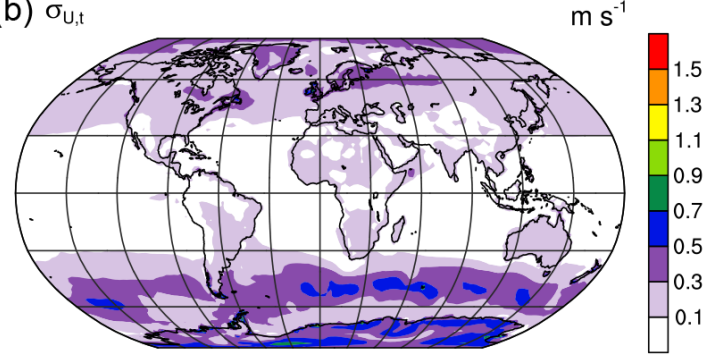

(d) $\sigma_{U, m}+\sigma_{U, I}$

$\mathrm{m} \mathrm{s}^{-1}$

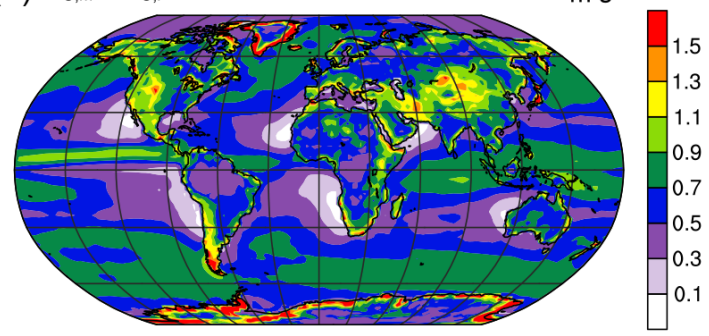

Figure 14. Annual mean sub-grid standard deviation of surface wind speed in CAM5: (a) total (Eq. 19), (b) neutral/stable turbulent mixing (Eq. 20), (c) dry convective eddies (Eq. 21), (d) moist convective eddies over the ocean (Eqs. 23-24) and mesoscale flow over land (Eq. 27).

Table 1. List of CAM5 simulations discussed in Sect. 5. DU and SS refer to dust and sea salt emissions, respectively. "With PDF" means the Weibull distribution of wind speed is used in the emission calculations (cf. Sect. 2.5). "Without PDF" means the enhancement of grid-box mean wind speed is taken into account, but the emission calculations use only the (enhanced) mean wind speed, not the Weibull PDF.

\begin{tabular}{|c|c|c|c|c|c|}
\hline \multirow[t]{2}{*}{ Simulation } & \multicolumn{4}{|c|}{ Source of sub-grid wind variability } & \multirow{2}{*}{$\begin{array}{c}\text { Dust } \\
\text { Emission } \\
\text { factor }\end{array}$} \\
\hline & $\begin{array}{l}\text { Turbulence } \\
\text { (Eq. 20) }\end{array}$ & $\begin{array}{l}\text { Dry convective eddy } \\
\text { (Eq. 21) }\end{array}$ & $\begin{array}{l}\text { Moist convective eddy } \\
\text { (ocean; Eqs. } 23 \text { and } 24 \text { ) }\end{array}$ & $\begin{array}{l}\text { Mesoscale flows over topography } \\
\text { (land; Eqs. } 26 \text { and 27) }\end{array}$ & \\
\hline NOSG & - & - & - & - & $0.35^{-1}$ \\
\hline CTRL & - & DU; without PDF & - & - & $0.35^{-1}$ \\
\hline EXP1 & - & DU + SS; with PDF & - & - & $0.35^{-1}$ \\
\hline EXP2 & DU + SS; with PDF & $\mathrm{DU}+\mathrm{SS} ;$ with PDF & - & - & $0.35^{-1}$ \\
\hline EXP3 & DU + SS; with PDF & DU + SS; with PDF & $\mathrm{DU}+\mathrm{SS}$; with PDF & DU + SS; with PDF & $0.35^{-1}$ \\
\hline EXP4 & $\mathrm{DU}+\mathrm{SS} ;$ with PDF & $\mathrm{DU}+\mathrm{SS}$; with PDF & $\mathrm{DU}+\mathrm{SS}$; with PDF & $\mathrm{DU}+\mathrm{SS}$; with PDF & $0.57^{-1}$ \\
\hline
\end{tabular}

\subsection{Online calculated sub-grid-scale wind variability}

Annual averages of the estimated sub-grid standard deviation of surface wind speed in CAM5 are presented in Fig. 14a, and the individual components are shown in Fig. 14b-d. Strong SGVs are associated with complex topography, midlatitude storm tracks, the trade winds, and tropical convection. Over the ocean, moist convective eddies are the most important contributor to wind SGV in the tropics (Fig. 14d), while dry convective eddies are the main contributor in the trade wind regions and above warm ocean currents (Fig. 14c). Over the continents, strong wind variabilities are associated with sub-grid topography and dry convective eddies (Fig. 14c-d). The impact of neutral/stable turbulent mixing is seen mainly in mid- and high-latitude regions (Fig. 14b).
Since the empirical parameterizations for $\sigma_{U, \mathrm{~m}}$ and $\sigma_{U, 1}$ were derived from the ECMWF analysis, the wind SGV in Fig. 14d agree reasonably well with the diagnostic results shown in Fig. 2f for the ECMWF data. The discrepancies over the ocean are attributable to fitting error and differences in the simulated precipitation rates in the two models. Over the continents, the discrepancies are likely caused by the different grid-box mean winds, and the use of a timeindependent coefficient $D$.

\subsection{Sensitivity experiments}

To evaluate the impact of different sources of wind SGV on the aerosol climatology in CAM5, a series of simulations were performed (Table 1). Experiment CTRL uses the default configuration of CAM5, in which the impact of dry convective eddies is taken into account when estimating the 
grid-box mean wind speed $\bar{U}_{\text {adj }}$ (Eq. 7). $\bar{U}_{\text {adj }}$ is used for calculating dust emission, while the parameterization of sea salt emission does not account for sub-grid wind variability (Eq. 2). Simulation EXP1 is similar to CTRL in that only dry convective eddies are considered for the wind SGV. The differences are that (i) the dust emissions are calculated using the wind speed PDF (Eq. 9), and (ii) the same PDF-based method is also applied to sea salt emission (Eq. 8). EXP2 extends EXP1 by adding the contribution of turbulence in neutral and stable boundary layers, and EXP3 further extends EXP2 by including the impact of moist convective eddies over the ocean and topography-related small-scale motions over land. For completeness, we also conducted a simulation called NOSG, in which the dust emission is calculated using the speed of resolved wind $|\overline{\boldsymbol{v}}|$ instead of $\bar{U}_{\text {adj }}$; in other words, NOSG does not include any effect of sub-grid wind variability on dust emission. The simulations NOSG, CTRL, EXP1, EXP2, and EXP3 are analyzed in Sect. 5.3 to quantify the contribution of different sources of wind variability to the emission and concentration of sea salt and dust aerosols.

As is shown later in Sects. 5.3, EXP3 features considerably stronger dust emission and higher dust loading. In global aerosol-climate models, it is a common practice to apply a constant scaling factor to the dust emission, for the purpose of adjusting the global mean dust AOD (aerosol optical depth) as well as the aerosol induced radiative forcing. The default scaling factor in CAM5 for the $2^{\circ}$ finite-volume dynamical core is $0.35^{-1}$ (here we follow the form of the scaling factor defined in the model). This value is used in NOSG, CTRL, EXP1, EXP2 and EXP3. When discussing the aerosol climatology in Sect. 5.4, we also present an additional simulation, EXP4, which used the same configuration as EXP3, but the dust emission factor is adjusted to $0.57^{-1}$, which brings the global and annual mean dust emission flux back to the value of the CTRL simulation.

\subsection{Contribution of individual sources of wind variability to aerosol emission and optical depth}

The impacts of wind SGV on sea salt emission and sea salt AOD at $550 \mathrm{~nm}$ are presented in Fig. 15 and Table 2. In the default model (Fig. 15a and b), the strongest sea salt emission occurs in the mid-latitude storm tracks where the majority of the released particles are subsequently removed by precipitation. The trade wind regions have moderate emission but very weak wet removal, which leads to high sea salt concentrations. In the deep tropics, the default model predicts very low emission because the impact of frequent and vigorous convective activity on surface wind SGV is not considered, and the grid-box mean wind speed is low. The low emission, in combination with strong removal associated with the parameterized convection, results in low sea salt AOD in regions of strongest convective precipitation.

The impacts of sub-grid wind variability on sea salt emission and optical depth are generally small and spatially ho- mogenous except in the Inter Tropical Convergence Zone (ITCZ). Taking into account the dry convective eddies $\left(\sigma_{U, \mathrm{~d}}\right)$ leads to a global mean increase of $2.48 \%$ in sea salt emission, and the regional increases are of similar magnitude (EXP1 in Table 2). The impact of neutral and stable turbulence $\left(\sigma_{U, t}\right)$ is smaller, less than $2 \%$ both regionally globally (EXP2 minus EXP1 in Table 2). Including moist convective eddies $\left(\sigma_{U, \mathrm{~m}}\right)$ further increases the emission fluxes by about $4 \%$ (EXP3 minus EXP2 in Table 2).

Within the ITCZ, the sub-grid wind variability estimated using our empirical relationships results in 10-35\% increases compared to the default model in the annual mean sea salt emission (Fig. 15e), and 10-25\% increases in sea salt AOD (Fig. 15f), mainly due to the moist convective eddies. However, since the resolved-scale wind speed is low in the ITCZ and the wet removal is strong, the contribution of these regions to the global total sea salt budget is small. In terms of global and annual average, the increase in sea salt emission is $7.48 \%$ (Table 2) when comparing EXP3 with CTRL. An additional sensitivity experiment was conducted using the formula of Redelsperger et al. (2000) for the moist convective eddies. The strongest enhancement of sea salt emission exceeded $100 \%$ in the ITCZ, while the resulting emission fluxes remained a factor of 5-10 weaker than in the storm tracks, and the increases in sea salt AOD were generally below $50 \%$. Although the Redelsperger et al. (2000) formula leads to higher wind SGV than our empirical fitting derived from the ECMWF analysis, the impact on the simulated sea salt emission and AOD is still small in terms of global mean and geographical distribution.

The simulated dust emission and optical depth are more sensitive to sub-grid wind variability than sea salt. Table 3 compares dust emissions in the major source regions. In both the control simulation and EXP1, dry convective eddies are taken into account when estimating the grid-box mean wind speed for dust emission; however, using multiple wind samples instead of the mean value leads to about $30 \%$ emission increases in Africa and Asia, and even larger differences in North America and South America (EXP1 in Table 3). This reflects the strong nonlinearity of the dust emission parameterization. Part of the nonlinearity comes from the fact that the parameterization requires the characteristic friction velocity $u_{* \mathrm{~s}_{j}}$ to exceed the threshold value $u_{* \mathrm{t}}$ in order for dust emission to occur (cf. Eq. 5).

The neutral/stable turbulence has relatively small impact. This result is consistent with the work of Cakmur et al. (2004). Taking into account neutral/stable turbulence leads to about a $3 \%$ increase in the global mean dust emission (EXP2 minus EXP1 in Table 3). The corresponding AOD changes (at $550 \mathrm{~nm}$ ) are negligible (not shown). In contrast, considering the small-scale motions related to sub-grid topography results in a $23 \%$ increase of the annual mean global dust emission (comparing EXP3 with EXP2 in Table 3). The regional enhancements are about $13 \%$ in North Africa, and $30-40 \%$ in Asia. In Table 3 we also included the emission 
Table 2. Simulated annual mean global and regional sea salt emissions $\left(\mathrm{Tg} \mathrm{yr}^{-1}\right)$ for the year 2006. Numbers in parenthesis are the relative differences with respect to the default model (CTRL). Meanings of the simulation short names are explained in Table 1. NOSG and EXP4 are not included here because they are identical to CTRL and EXP3, respectively, in terms of the sea salt emission parameterization.

\begin{tabular}{lllll}
\hline Simulation & Global & $\begin{array}{l}\text { Northern Hemisphere } \\
\left(30-60^{\circ} \mathrm{N}\right)\end{array}$ & $\begin{array}{l}\text { Southern Hemisphere } \\
\left(30-60^{\circ} \mathrm{S}\right)\end{array}$ & $\begin{array}{l}\text { Tropics } \\
\left(20^{\circ} \mathrm{S}-20^{\circ} \mathrm{N}\right)\end{array}$ \\
\hline CTRL & 5011.3 & 854.8 & 2504.8 & 925.8 \\
EXP1 & $5135.6(+2.48 \%)$ & $880.5(+3.00 \%)$ & $2547.3(+1.69 \%)$ & $956.0(+3.27 \%)$ \\
EXP2 & $5198.9(+3.74 \%)$ & $891.8(+4.33 \%)$ & $2591.3(+3.45 \%)$ & $958.2(+3.50 \%)$ \\
EXP3 & $5386.4(+7.48 \%)$ & $929.9(+8.78 \%)$ & $2678.1(+6.91 \%)$ & $996.4(+7.63 \%)$ \\
\hline
\end{tabular}

(a) Sea Salt Emission, CTRL

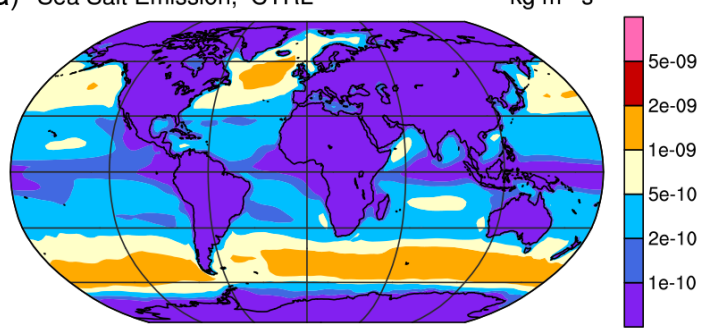

(c)

c) Sea Salt Emission, EXP3-CTRL

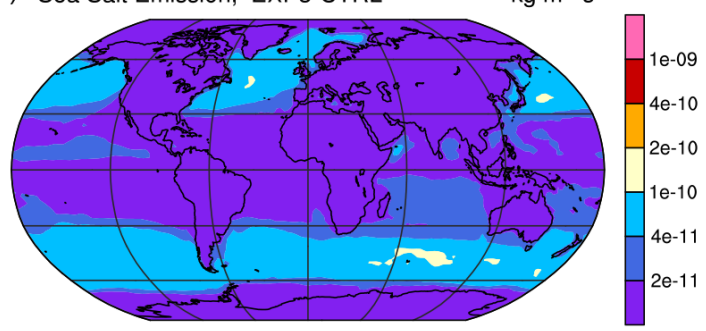

(e)

(e) Sea Salt Emission, (EXP3-CTRL) / CTRL

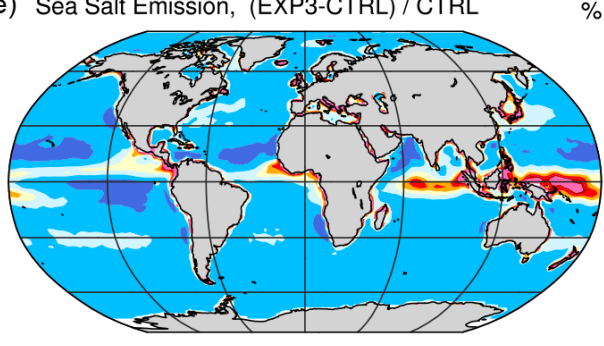

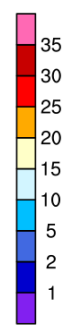

(b) Sea Salt AOD, CTRL

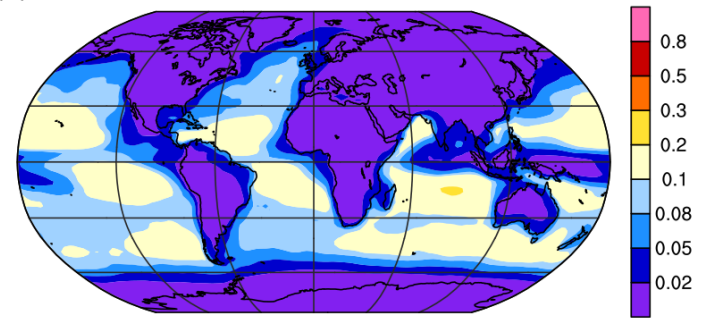

(d) Sea Salt AOD, EXP3-CTRL

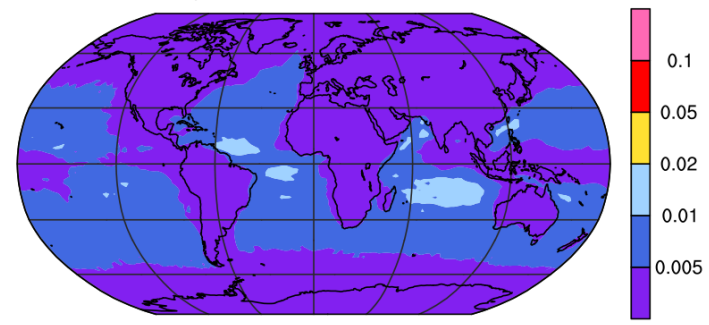

(f) Sea Salt AOD, (EXP3-CTRL) / CTRL

$\%$

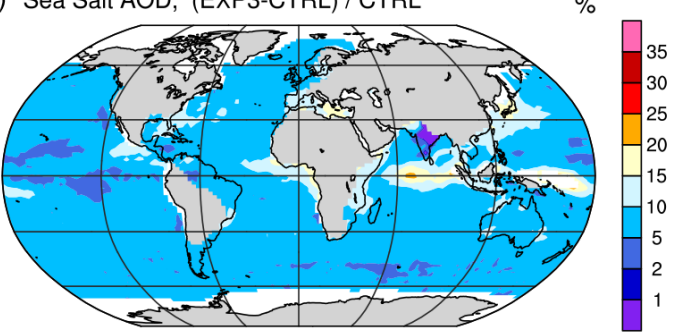

Figure 15. Top row: year 2006 mean sea salt emission flux $\left(\mathrm{kg} \mathrm{m}^{-2} \mathrm{~s}^{-1}\right)$ and sea salt AOD (unitless) at $550 \mathrm{~nm}$ in the nudged CAM5 simulation (CTRL); Second row: differences between EXP3 and CTRL. Bottom row: relative differences between EXP3 and CTRL. In the bottom row, locations that have emission fluxes less than $1 \times 10^{-12} \mathrm{~kg} \mathrm{~m}^{-2} \mathrm{~s}^{-1}$ or sea salt AOD $<0.01$ in the CTRL simulation are masked out.

fluxes from the NOSG simulation. Combined with EXP1, these numbers quantify the total impact of dry convective eddies. From the table, it is clear that dry convective eddies and mesoscale flows associated with sub-grid-scale topography are the most important factors that affect dust emission in CAM5.

In Fig. 16, the geographical distributions of annual mean dust emission flux and AOD are shown for CTRL, together with the differences between EXP3 and CTRL. For both the emission and the AOD, there is little change in the global pat- terns, except that the increases in Australia are considerable smaller than those in Africa and Asia.

\subsection{Comparison with AOD observations}

The diagnostics above showed that applying the PDF method to take into account sub-grid wind speed variability leads to considerable increases in the emission and loading of dust aerosols. To evaluate how much the increases affect the agreement and discrepancies between model simulation and 
Table 3. Simulated annual mean global and regional dust emission $\left(\mathrm{Tg} \mathrm{yr}^{-1}\right)$ for the year 2006. Numbers in parenthesis are the relative differences with respect to the default model (CTRL). The experiment configurations are explained in Table 1.

\begin{tabular}{llllllll}
\hline Simulation & Global & $\begin{array}{l}\text { North Africa } \\
\left(10-30^{\circ} \mathrm{N},\right. \\
\left.20^{\circ} \mathrm{W}-40^{\circ} \mathrm{E}\right)\end{array}$ & $\begin{array}{l}\text { East Asia } \\
\left(30-50^{\circ} \mathrm{N},\right. \\
\left.80-120^{\circ} \mathrm{E}\right)\end{array}$ & $\begin{array}{l}\text { West Asia } \\
\left(15-50^{\circ} \mathrm{N},\right. \\
\left.40-70^{\circ} \mathrm{E}\right)\end{array}$ & $\begin{array}{l}\text { Australia } \\
\left(10-40^{\circ} \mathrm{S},\right. \\
\left.110-140^{\circ} \mathrm{E}\right)\end{array}$ & $\begin{array}{l}\text { North America } \\
\left(10-60^{\circ} \mathrm{N},\right. \\
\left.30-140^{\circ} \mathrm{W}\right)\end{array}$ & $\begin{array}{l}\text { South America } \\
\left(0-60^{\circ} \mathrm{S},\right. \\
\left.40-80^{\circ} \mathrm{W}\right)\end{array}$ \\
\hline NOSG & $3365.0(-14.3 \%)$ & $1588.4(-15.6 \%)$ & $551.8(-13.7 \%)$ & $522.4(-15.6 \%)$ & $137.5(-11.8 \%)$ & $1.74(-24.0 \%)$ & $7.57(-39.4 \%)$ \\
CTRL & 3927.9 & 1880.7 & 639.3 & 619.3 & 155.9 & 2.29 & 12.5 \\
EXP1 & $5015.5(+27.7 \%)$ & $2447.3(+30.1 \%)$ & $876.0(+37.0 \%)$ & $825.2(+33.2 \%)$ & $149.9(-3.9 \%)$ & $3.76(+64.4 \%)$ & $29.0(+132.0 \%)$ \\
EXP2 & $5124.5(+30.5 \%)$ & $2500.6(+33.0 \%)$ & $875.8(+37.0 \%)$ & $848.3(+37.0 \%)$ & $174.2(+11.7 \%)$ & $3.88(+69.5 \%)$ & $29.2(+133.6 \%)$ \\
EXP3 & $6027.9(+53.5 \%)$ & $2736.1(+45.5 \%)$ & $1133.8(+77.4 \%)$ & $1048.3(+69.3 \%)$ & $188.0(+20.6 \%)$ & $5.03(+119.7 \%)$ & $45.0(+259.5 \%)$ \\
EXP4 & $4024.9(+2.47 \%)$ & $1829.1(-2.74 \%)$ & $798.8(+25.0 \%)$ & $683.7(+10.4 \%)$ & $120.3(-22.9 \%)$ & $3.25(+42.1 \%)$ & $28.0(+123.5 \%)$ \\
\hline
\end{tabular}

(a) Dust Emission, CTRL

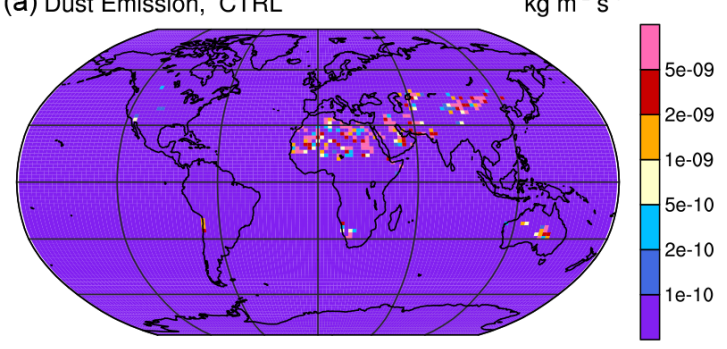

(c) Dust Emission, EXP3-CTRL

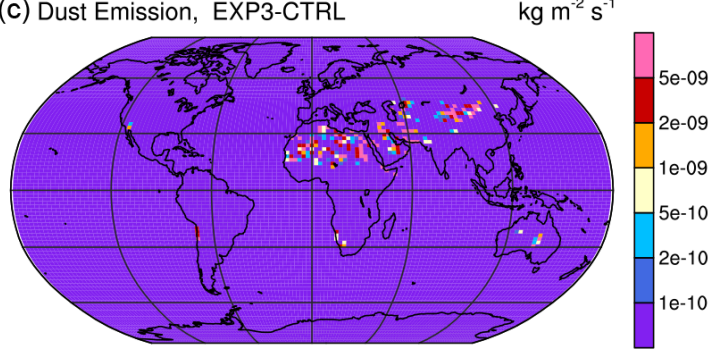

(e) Dust Emission, (EXP3-CTRL) / CTRL

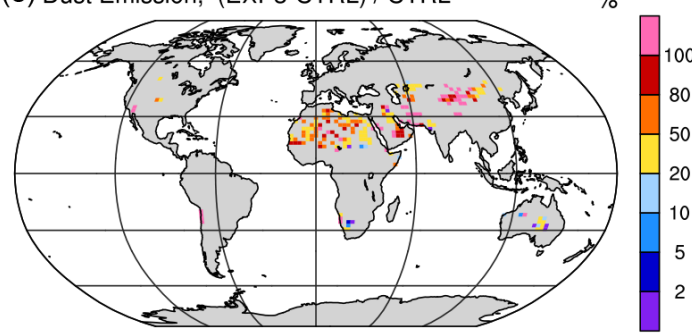

(b) Dust AOD, CTRL

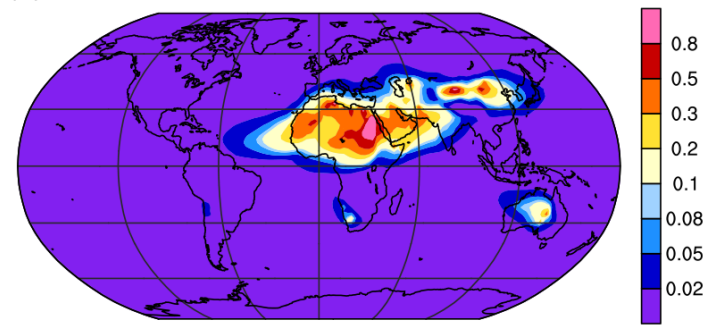

(d) Dust AOD, EXP3-CTRL

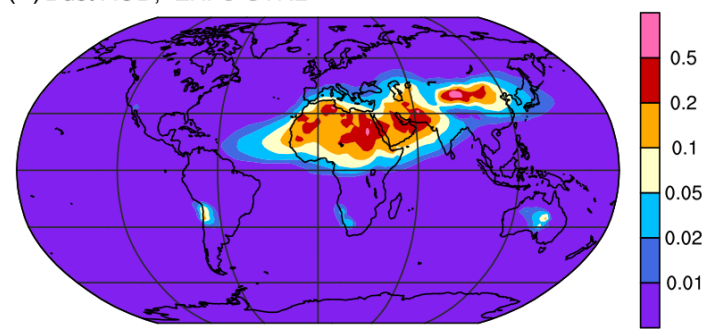

(f) Dust AOD, (EXP3-CTRL) / CTRL

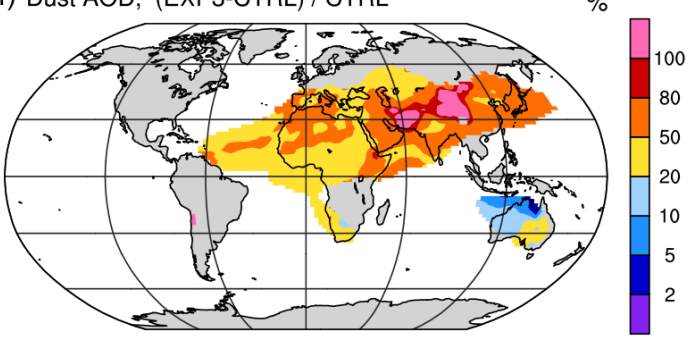

Figure 16. As in Fig. 15 but for dust emission and dust AOD at $550 \mathrm{~nm}$. The threshold values for masking out differences in the bottom row are $1 \times 10^{-10} \mathrm{~kg} \mathrm{~m}^{-2} \mathrm{~s}^{-1}$ for emission and 0.01 for AOD.

observation, the simulated AOD at $550 \mathrm{~nm}$ is compared with satellite retrievals in dust source regions.

Figure 17 compares the annual mean total AOD at $550 \mathrm{~nm}$ against satellite retrievals obtained by the Multi-angle Imaging SpectroRadiometer (MISR) in 14 major dust source regions (Table 4). The definition and indexing of the 14 regions follow Zender and Kwon (2005). Model data are sampled at the satellite local overpass time of 13:30, and are masked out when the corresponding MISR record indicates missing data. Note that we modified the model source code to calcu- late the aerosol optical properties at each model time step, rather than doing the calculation when the radiation calculation is called every $2 \mathrm{~h}$ as in the standard model. The comparison indicates that, except in regions 3, 8, and 5 (North America and South Africa), the total AOD in EXP3 is higher than that of CTRL by 14-71\%, and higher than the MISR data by $6-167 \%$ (Fig. 17). The largest differences are found in regions 2 and 9 (North Africa), 7 and 13 (China), and 1012 (Arabia), all of which correspond to relatively large values of the coefficient $D$ in Fig. 10, which reflect the impact 
Table 4. Definition of the 14 major dust source regions in which the simulated and MISR retrieved AOD are compared in Fig. 17. The relative differences between the simulated and MISR retrieved AOD are also shown.

\begin{tabular}{|c|c|c|c|c|c|}
\hline Number & Region & MISR & CTRL vs. MISR & EXP3 vs. MISR & EXP4 vs. MISR \\
\hline 1 & Eastern Sahel $\left(10-15^{\circ} \mathrm{N}, 10^{\circ} \mathrm{W}-20^{\circ} \mathrm{E}\right)$ & 0.243 & $-11.1 \%$ & $+6.30 \%$ & $-9.41 \%$ \\
\hline 2 & Bodele depression $\left(15-20^{\circ} \mathrm{N}, 10-20^{\circ} \mathrm{E}\right)$ & 0.526 & $-7.03 \%$ & $+33.1 \%$ & $-6.54 \%$ \\
\hline 3 & Western United States and Mexico $\left(25-35^{\circ} \mathrm{N}, 110-100^{\circ} \mathrm{W}\right)$ & 0.147 & $-57.8 \%$ & $-56.6 \%$ & $-57.7 \%$ \\
\hline 4 & Lake Eyre Basin $\left(30-25^{\circ} \mathrm{S}, 136-145^{\circ} \mathrm{E}\right)$ & 0.130 & $+16.2 \%$ & $+39.6 \%$ & $-0.62 \%$ \\
\hline 5 & Botswana $\left(25-20^{\circ} \mathrm{S}, 20-30^{\circ} \mathrm{E}\right)$ & 0.157 & $-40.8 \%$ & $-38.6 \%$ & $-42.5 \%$ \\
\hline 6 & Gobi Desert $\left(42.5-45^{\circ} \mathrm{N}, 105-110^{\circ} \mathrm{E}\right)$ & 0.219 & $-5.48 \%$ & $+65.2 \%$ & $+18.4 \%$ \\
\hline 7 & Chinese Loess Plateau $\left(32.5-37.5^{\circ} \mathrm{N}, 105-110^{\circ} \mathrm{E}\right)$ & 0.385 & $-22.9 \%$ & $+8.22 \%$ & $-14.9 \%$ \\
\hline 8 & Great Salt Lake $\left(40-42.5^{\circ} \mathrm{N}, 115-112.5^{\circ} \mathrm{W}\right)$ & 0.156 & $-76.9 \%$ & $-74.9 \%$ & $-76.2 \%$ \\
\hline 9 & Zone of Chotts $\left(32.5-35^{\circ} \mathrm{N}, 5-10^{\circ} \mathrm{E}\right)$ & 0.312 & $+56.1 \%$ & $+170.1 \%$ & $+86.4 \%$ \\
\hline 10 & Tigris-Euphrates $\left(27.5-32.5^{\circ} \mathrm{N}, 45-57.5^{\circ} \mathrm{E}\right)$ & 0.320 & $+1.56 \%$ & $+57.0 \%$ & $+11.9 \%$ \\
\hline 11 & Saudi Arabia $\left(20-25^{\circ} \mathrm{N}, 47.5-52.5^{\circ} \mathrm{E}\right)$ & 0.501 & $-12.6 \%$ & $+29.9 \%$ & $-7.63 \%$ \\
\hline 12 & Oman $\left(17.5-20^{\circ} \mathrm{N}, 52.5-57.5^{\circ} \mathrm{E}\right)$ & 0.388 & $+1.80 \%$ & $+47.6 \%$ & $+5.66 \%$ \\
\hline 13 & Tarim Basin $\left(35-40^{\circ} \mathrm{N}, 75-90^{\circ} \mathrm{E}\right)$ & 0.347 & $-30.8 \%$ & $+28.4 \%$ & $-3.91 \%$ \\
\hline 14 & Thar Desert $\left(25-30^{\circ} \mathrm{N}, 70-75^{\circ} \mathrm{E}\right)$ & 0.421 & $-24.0 \%$ & $+12.4 \%$ & $-16.1 \%$ \\
\hline
\end{tabular}
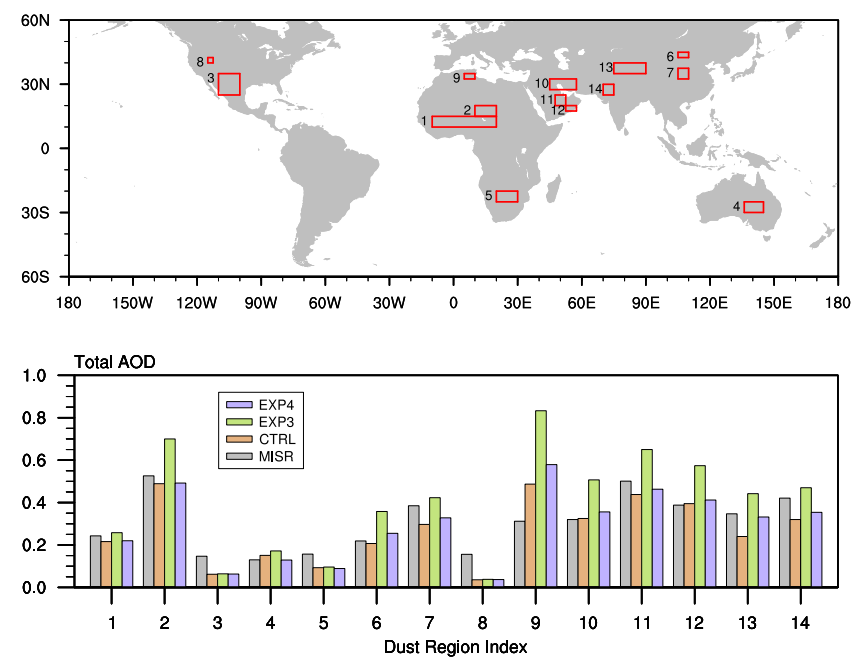

Figure 17. Satellite retrieved AOD from MISR (Multi-angle Imaging Spectro-Radiometer) and simulated regional average AOD at $550 \mathrm{~nm}$ at 14 major dust source regions $\left(\mathrm{Tg} \mathrm{yr}^{-1}\right)$ for the year 2006. These regions were defined in the work of Zender and Kwon (2005) based on the dust source regions identified by Prospero et al. (2002) and data from Torres et al. (2002). Region definition and the data used to plot the lower panel are given Table 4.

of complex sub-grid-scale topography. By changing the dust emission scale factor from $0.35^{-1}$ (EXP3) to $0.57^{-1}$ (EXP4), the global mean emission flux is brought back to the value in CTRL with a less than $5 \%$ difference. Consequently, the regional AOD values also become similar to those in CTRL (Fig. 17).

In Fig. 18, annual mean global maps of dust emission and dust AOD at $550 \mathrm{~nm}$ are presented for EXP4. The absolute and relative differences with respect to the default model are also shown. While the geographical distributions are similar in both model versions, taking into account wind SGV then retuning the global mean leads to dust AOD increases in Asia and northwest Africa, and decreases in Australia and tropical Africa (Fig. 18d and f). A comparison between the emission flux difference in Fig. 18c and e with the wind SGV maps in Fig. 14 suggests that the grid cells with decreased emissions are typically associated with smaller wind variabilities related to unresolved topography, while those grid cells with increased emissions are associated with stronger wind variabilities caused by topography and/or dry convective eddies.

In addition to MISR, we have compared the simulated AOD with high-frequency measurements from the Aerosol Robotic Network (AERONET) sites close to the dust source regions. It turns out that the AERONET measurements falling in our simulation period are located in regions where CTRL and EXP4 give very similar dust AOD. The comparison thus did not indicate systematic improvement or degradation in terms of the agreement between model results and measurements. In the Taklamakan Desert, southeast Iran, and Pakistan where AOD in EXP4 is considerably higher than that in CTRL (Fig. 18), it is not yet known how the two simulations compare with observations due to the unfortunate lack of data.

\subsection{Dust emission frequency}

In Fig. 19a-c, frequency distributions of the simulated dust emission fluxes are shown for three regions: Northwest China $\left(35-50^{\circ} \mathrm{N}, 80-110^{\circ} \mathrm{E}\right)$, North Africa $\left(10-30^{\circ} \mathrm{N}, 10^{\circ} \mathrm{W}-\right.$ $\left.20^{\circ} \mathrm{E}\right)$, and Australia $\left(20-30^{\circ} \mathrm{S}, 110-150^{\circ} \mathrm{E}\right)$. To derived those distributions, hourly emission fluxes of the year 2006 at individual grid cells were treated as separate samples.

In Northwest China and North Africa, introducing subgrid wind variability without tuning the global mean dust emission leads to more frequent dust emission in all nonzero flux bins (Fig. 19a-b, EXP3 versus CTRL). Re-tuning the emission results in less frequent occurrence of stronger 
(a) Dust Emission, EXP4

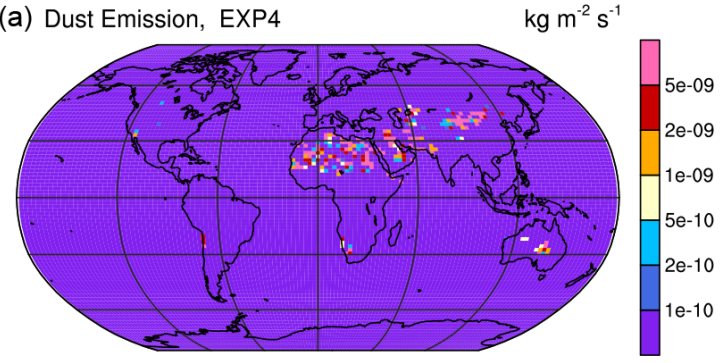

(c) Dust Emission, EXP4-CTRL

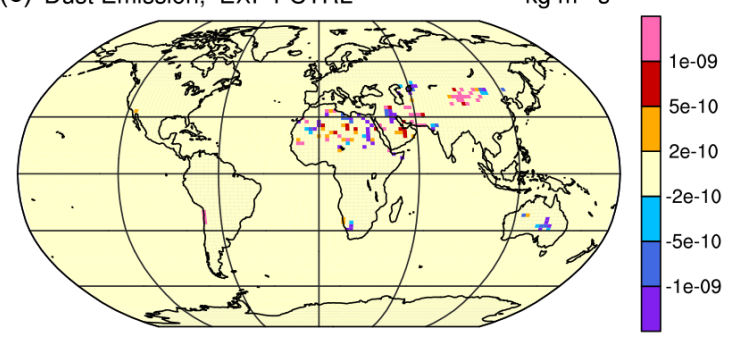

(e) Dust Emission, (EXP4-CTRL) / CTRL

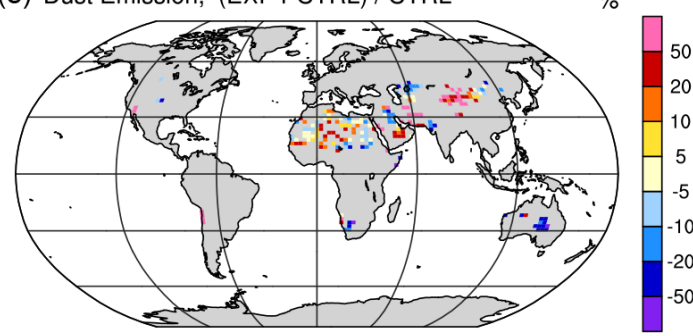

(b) Dust AOD, EXP4

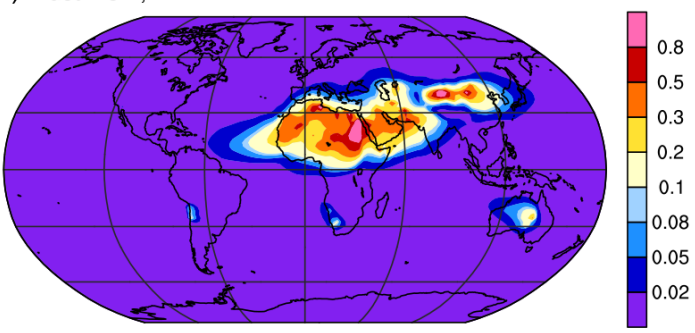

(d) Dust AOD, EXP4-CTRL

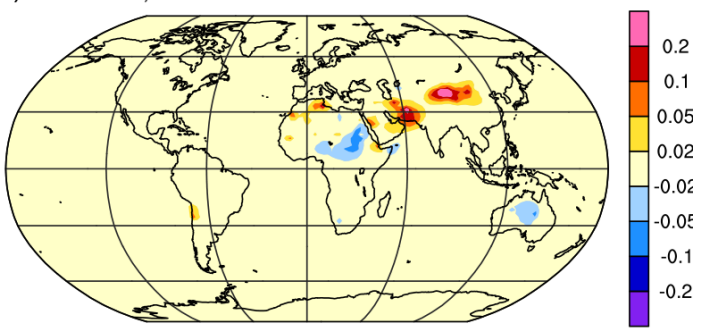

(f) Dust AOD, (EXP4-CTRL) / CTRL

$\%$

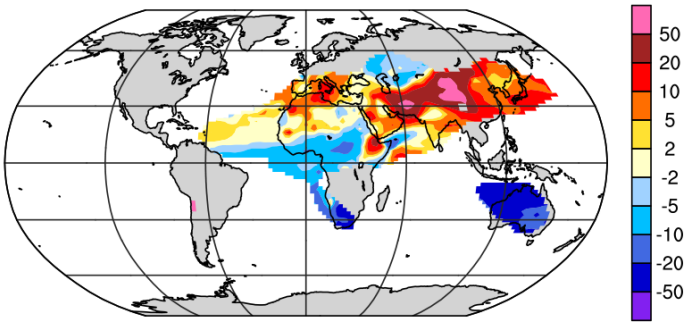

Figure 18. Top row: year 2006 mean dust emission flux $\left(\mathrm{kg} \mathrm{m}^{-2} \mathrm{~s}^{-1}\right)$ and dust AOD (unitless) at 550 nm in EXP4; Second row: differences between EXP4 and CTRL. Bottom row: relative differences between EXP4 and CTRL. In the bottom row, locations that have emission fluxes less than $1 \times 10^{-10} \mathrm{~kg} \mathrm{~m}^{-2} \mathrm{~s}^{-1}$ or AOD $<0.01$ in the CTRL simulation are masked out.

emissions and more frequent occurrence of weaker emissions (Fig. 19a-b, EXP4 versus CTRL). Because the retuning is implemented globally using a constant scaling factor, the same qualitative change is seen also in regions where the sub-grid wind variability is relatively small (e.g., Australia, Fig. 19c). The lower row of Fig. 19 shows the relative contribution of each flux range to the total dust emission in the three locations, again derived from hourly data of 2006. The three panels further confirm that after the retuning, EXP4 features smaller contributions from stronger emission events, and larger contributions from weaker emission events. Given that the flux samples are spatial averages in $2^{\circ}$ model grid cells, the shift of emission distribution seems physically plausible.

Ideally it would be nice to use observational data sets to evaluate whether such a shift also makes the simulated emissions more realistic. For example, Schepanski et al. (2007) presented seasonal dust source area maps for the Sahara and Sahel region derived from IR-channel images of Meteosat Second Generation. A quantitative comparison between our simulations and their results is however difficult, because the absolute value of the emission frequency depends strongly on the dust mass flux threshold that is used when identifying an emission event. In the work of Schepanski et al. (2007), dust emission was identified by visually detecting dust plumes, then visually tracing the plume patterns back to their origin by inspecting consecutive images during dust mobilization and transport events. In order to directly compare their maps with our simulations, one would need to implement a satellite simulator in our model, produce the IR-channel images, then apply the same human-involved method of visual dust activation identification. Such an evaluation is impractical in our study; below we limit ourselves to a qualitative comparison with the results of Schepanski et al. (2007).

Maps of seasonal dust emission frequencies in Africa and Asia are presented for CTRL and EXP4 in Fig. 20. Since it is unclear what dust emission flux thresholds the maps of Schepanski et al. (2007) correspond to, we chose a somewhat arbitrary (but low) threshold of $10^{-9} \mathrm{~kg}^{-2} \mathrm{~s}^{-1}$. Figure 20 indicates that the inclusion of wind SGV generally increases the frequency of dust emission; this is consistent with the PDFs shown in Fig. 19. In addition, EXP4 features enhanced seasonal differences compared to CTRL: wind variability associated with dry convective eddies leads to considerably 

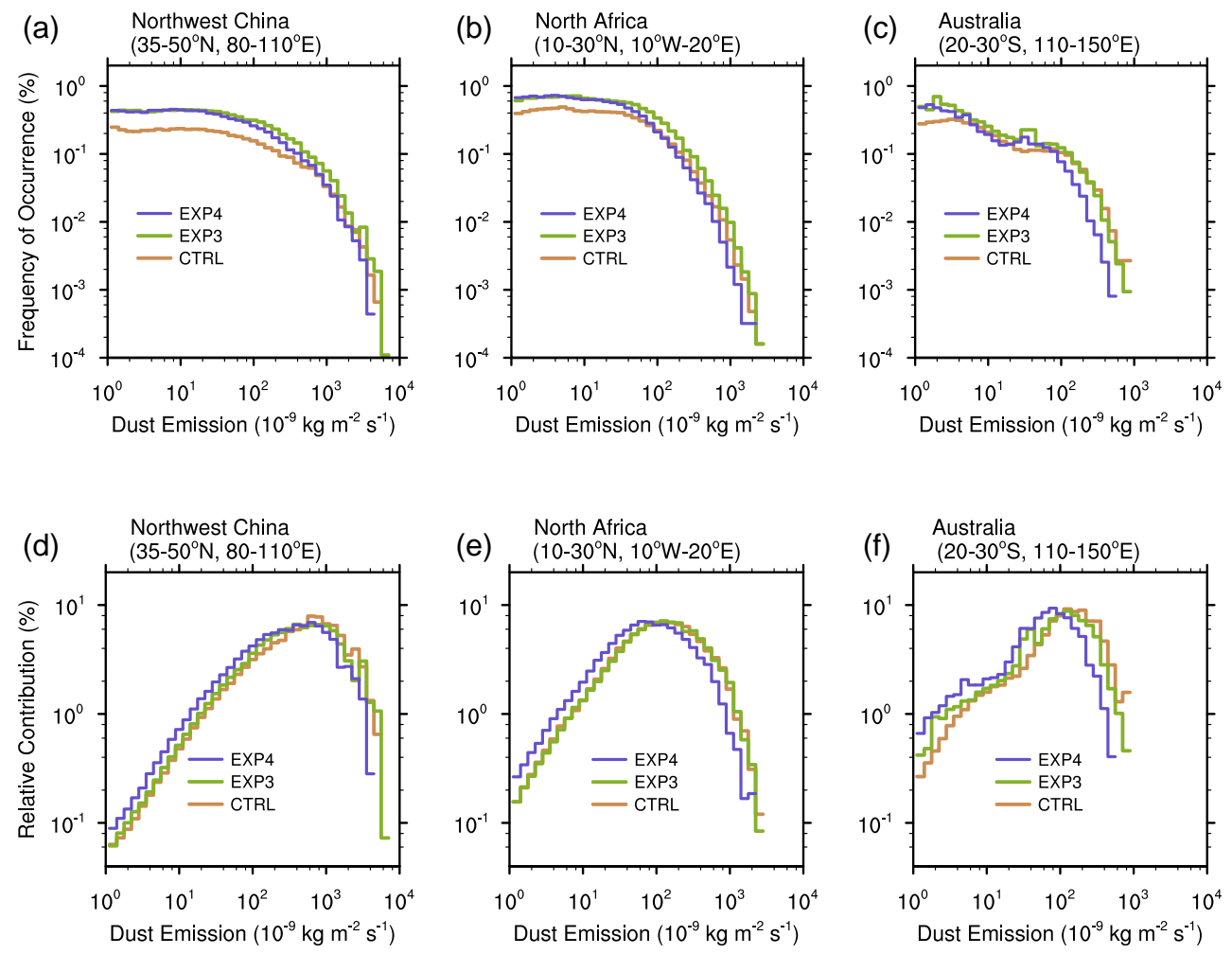

Figure 19. Upper row: frequency distribution of simulated dust emissions in (a) Northwest China, (b) North Africa, and (c) Australia. Lower row: relative contribution of each emission flux bin to the total emission in those three regions. The results were derived from hourly emission fluxes of the year 2006. All grid cells in each region were treated as individual samples.

more frequent dust emission in boreal spring/summer than in autumn/winter.

In terms of geographical distribution, Schepanski et al. (2007) showed seasonal shifts of dust emission patterns in North Africa. In our simulated, however, dust emissions largely occur at the same locations all year round, except in Northwest China where the source regions are larger in spring and summer. The frequency patterns in CTRL and EXP4 are similar, and both differ in the details from the maps of Schepanski et al. (2007). The same turned out to be true when we increased the emission flux threshold to higher values. Our analysis showed that the wind SGV changes the magnitudes of the emission frequency, but does not significantly change the spatial pattern. This is not surprising since apart from wind speed, the simulated dust emission also depends on other assumptions in the parameterization scheme as well as the surface properties in the model. Recently, Heinold et al. (2015) used the dust source area data derived based on Schepanski et al. (2007) and replaced the original source area parameterization over the Sahara Desert in ECHAM6-HAM2. They found the model predicts a more realistic geographical distribution using the new source map. In future studies, it would be useful to use this data set to constrain the dust emission calculation in CAM5 too.

\subsection{Comments on resolution sensitivity}

It is a common feature of many global aerosol-climate models (including CAM5) that the simulated surface wind speeds and aerosol emissions are sensitive to model resolution (e.g., Gläser et al., 2012). This is in fact the reason why the dust emission factor in Table 1 was introduced in the first place, and this parameter is often adjusted in simulations at different resolutions for the purpose of achieving the desired energy balance. Now that an empirical method has been developed in this study to account for the impact of sub-grid wind variability, a natural question to ask is whether this PDF-based method makes the dust emission parameterization scale-aware, and hence reduces the resolution sensitivity of the simulated dust emission. To answer this question, we first note that in this study, the sub-grid wind speed PDF is determined by the grid-box mean and standard deviation of the surface wind speed $\left(\bar{U}\right.$ and $\left.\sigma_{U}\right)$, which in turn depends on

i. the GCM-resolved surface wind $\bar{v}$;

ii. the various components of the sub-grid wind variability, namely, $\sigma_{U, \mathrm{t}}, \sigma_{U, \mathrm{~d}}, \sigma_{U, \mathrm{~m}}$, and $\sigma_{U, 1}$.

This study made an attempt to address the second aspect for a $\mathrm{GCM}$ resolution of $2^{\circ}$ lat $\times 2^{\circ}$ long. For other resolu- 

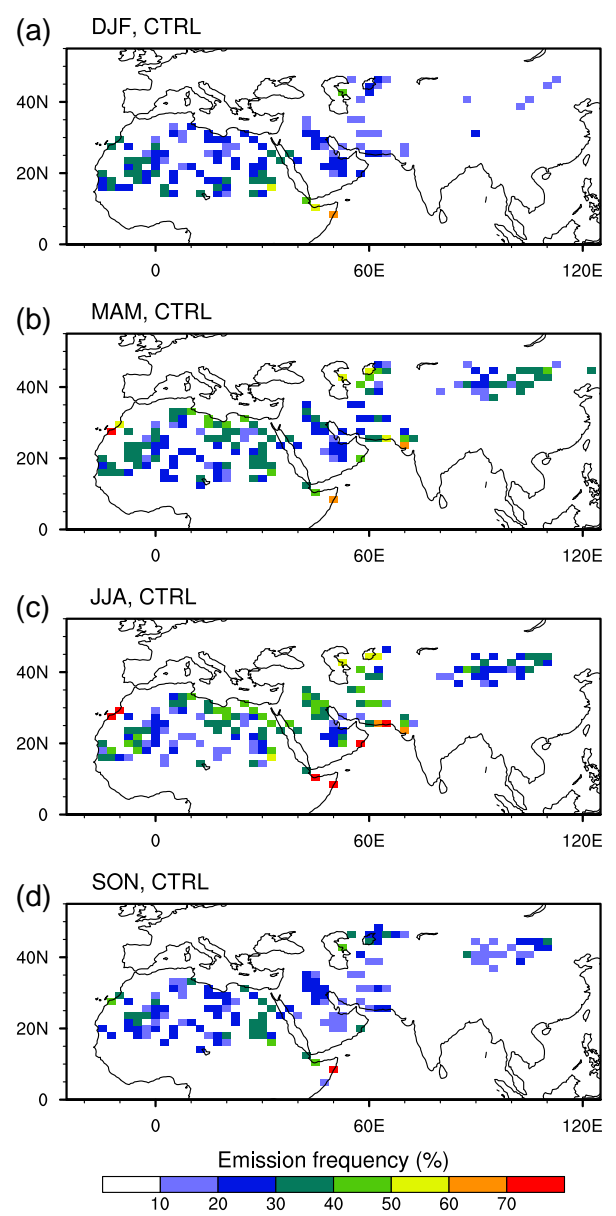
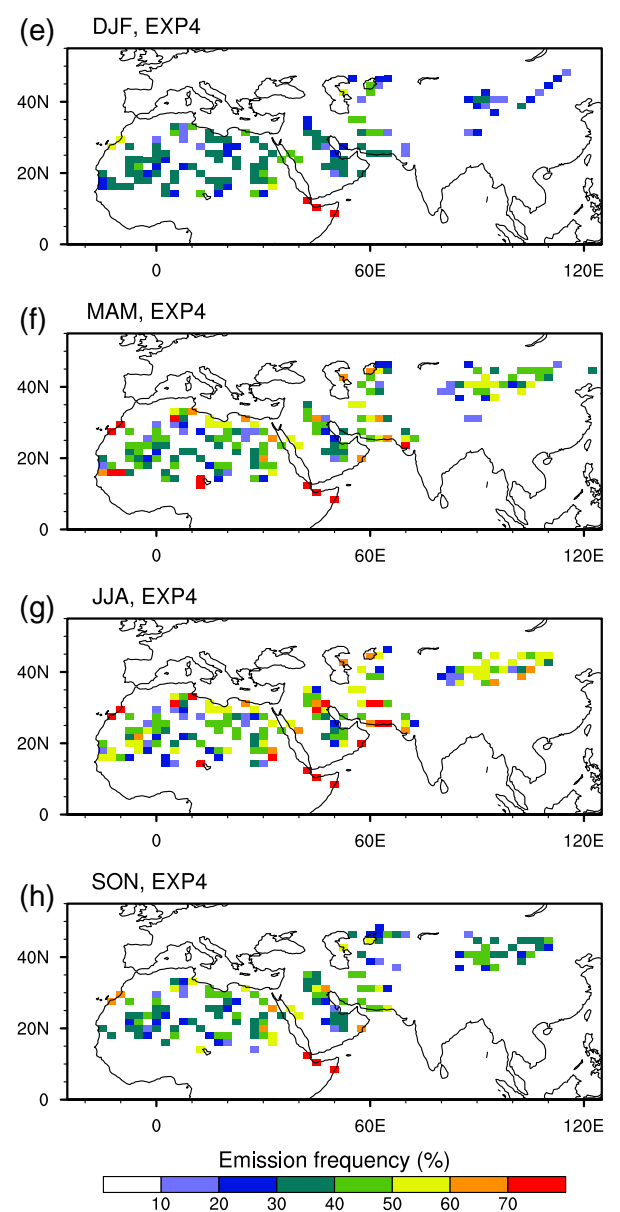

Figure 20. Frequency of occurrence (unit: \%) of dust emission fluxes stronger than $10^{-9} \mathrm{~kg}^{-2} \mathrm{~s}^{-1}$ in Africa and Asia in the CTRL simulation (left column) and in EXP4 (right column). Different rows correspond to different seasons: December-January-February (DJF), March-AprilMay (MAM), June-July-August (JJA), and September-October-November (SON).

tions, the coefficient $D$ used for estimating the topographyrelated wind variability (Eq. 27) needs to be re-derived using Eq. (26). Similarly, for aerosol emissions over the ocean, the coefficients in Eqs. (23) and (24) also need to be re-derived for different resolutions. In addition to $\sigma_{U}$, the resolved wind $\overline{\boldsymbol{v}}$ also determines the sub-grid wind speed distribution, and $\overline{\boldsymbol{v}}$ is mainly affected by the large-scale dynamics, convection parameterization, and surface properties. These aspects of an atmospheric GCM are out of the scope of the current work. The resolution sensitivity of dust emission can be removed when all model components are scale-aware. Since only part of the necessary conditions are addressed in this study, we do not expect the dust emissions simulated at different resolutions to agree with each other.

\section{Conclusions}

In this paper we evaluated the impact of sub-grid surface wind variability on sea salt and dust emissions in CAM5. The basic strategy is to calculate emission fluxes multiple times in each GCM grid cell using different samples of a wind speed distribution derived from model-predicted grid-box mean quantities.

Simplified diagnostic calculations were conducted first, using year 2011 of the ECMWF operational analysis $(15 \mathrm{~km}$ resolution), and two simulations with the WRF model at $3 \mathrm{~km}$ resolution, one for a $900 \mathrm{~km} \times 900 \mathrm{~km}$ domain over the Southern Ocean, and the other with the same domain size but located in western China near the Taklamakan Desert. The high-resolution meteorological data were regridded to coarse-resolution grids $\left(2^{\circ}\right.$ lat $\times 2^{\circ}$ long for ECMWF and $225 \mathrm{~km}$ resolution for WRF), and sea salt and dust emissions were calculated using both high- and coarse-resolution surface wind speeds then compared.

Sea salt emissions calculated using the coarse-resolution grid-box mean wind speed were reasonably accurate (with less than a few percent error) in terms of annual mean, but instantaneous emission fluxes were more severely underestimated at times. For dust emissions, non-negligible errors were seen both in instantaneous emissions and in annual av- 
erages, suggesting that the impact of sub-grid wind variability needs to be taken into account. It was also confirmed that when the mean and standard deviation of surface wind speed are known accurately, the Weibull distribution provides a good characterization of the probability distribution of the sub-grid wind speed, from which different samples can be drawn for the emission calculation.

In order to estimate the sub-grid wind speed distribution in the CAM5 global climate model using the available model-predicted physical quantities, we developed a method to approximate the sub-grid standard deviation of surface wind speed using four components. The contributions of neutral/stable turbulence and dry convective eddies were estimated using parameterizations from previous studies. The wind variabilities caused by moist convective eddy over the ocean and small-scale topography over land were estimated using empirical relationships derived from the $15 \mathrm{~km}$ ECMWF analysis of 2011. Evaluation against the year 2012 analysis of ECMWF showed that the empirical relationships can capture the sub-grid variability of surface wind speeds reasonably well. Further evaluation using the $3 \mathrm{~km}$ WRF simulations suggested that the formulae derived using the ECMWF analysis are not severely limited by the $15 \mathrm{~km}$ horizontal resolution.

The online calculated sub-grid wind speed distributions were used in the sea salt and dust emission parameterizations in CAM5 simulations of the year 2006 at $2^{\circ}$ horizontal resolution with 30 vertical levels. In terms of computational cost, the increase in total simulation time turned out to be less than $3 \%$. The CAM5 simulations confirm conclusions from the simplified diagnostic calculation that sub-grid wind variability has relatively small impacts on the annual mean emission of sea salt aerosols, but considerable influence on the emission of dust. Among the considered mechanisms, dry convective eddies and small-scale topography are the major causes of dust emission increases when sub-grid wind variability is taken into account. With all the four components included and no additional adjustment of uncertain parameters in the model, the simulated global and annual mean dust emission increase by about $50 \%$ compared to the default model. The dust AOD in the source regions in central and eastern Asia increases by more than $100 \%$, while that in North Africa, Arabia, and the downwind regions in East Asia increases between 50 and $100 \%$. Consequently, the total AOD simulated in dust source regions is considerably higher than both the default model and the MISR retrieval. By tuning the globally constant dust emission scale factor, the dust emission, AOD, and top-of-atmosphere radiative fluxes can be adjusted to the level of the default model, but the frequency distribution of dust emission changes, with more contribution from weaker events and less contribution from stronger events. In Africa and Asia, the integrated dust emission frequencies increase, and the seasonal variations are enhanced, while the geographical patterns of the emission frequency show little change.

\section{Code availability}

The CESM version 1.2.0 release can be obtained at http://www.cesm.ucar.edu/models/cesm1.2/. Code modifications for the sub-grid treatment of wind-driven aerosol emission calculations can be obtained from the corresponding author.

Acknowledgements. This work was supported by the U.S. Department of Energy (DOE) office of Science as part of the Scientific Discovery Through Advanced Computing (SciDAC) project on Multiscale Methods for Accurate, Efficient, and Scale-Aware Models of the Earth System. The Pacific Northwest National Laboratory is operated for DOE by Battelle Memorial Institute under contract DE-AC06-76RLO 1830. We appreciate the comments and suggestions from the two anonymous reviewers and from the editor. We thank Charlie Zender for making the Dust Entrainment and Deposition Model (DEAD) available for public access. We also are grateful to Phil Rasch and Po-Lun Ma (PNNL) for helpful discussions. Computational resources (ark:/85065/d7wd3xhc) at the NCAR-Wyoming Supercomputing Center were provided by the National Science Foundation and the State of Wyoming, and supported by NCAR's Computational and Information Systems Laboratory. Computational resources at the Pacific Northwest National Laboratory were provided by the PNNL Institutional Computing (PIC). The ECMWF operational analysis used in this study were obtained from the Research Data Archive (RDA) maintained by the Computational and Information Systems Laboratory (CISL) at the National Center for Atmospheric Research (NCAR). NCAR is sponsored by the National Science Foundation (NSF). The post-processing of model results was conducted using the Climate Data Operators (CDO, available at http://www.mpimet.mpg.de/cdo) and the NCAR Command Language (NCL, available at http://dx.doi.org/10.5065/D6WD3XH5).

Edited by: O. Boucher

\section{References}

Arakawa, A., Jung, J.-H., and Wu, C.-M.: Toward unification of the multiscale modeling of the atmosphere, Atmos. Chem. Phys., 11, 3731-3742, doi:10.5194/acp-11-3731-2011, 2011.

Banta, R. M., Pichugina, Y. L., and Brewer, W. A.: Turbulent velocity-variance profiles in the stable boundary layer generated by a nocturnal low-level jet, J. Atmos. Sci., 63, 2700-2719, doi:10.1175/JAS3776.1, 2006.

Bretherton, C. S. and Park, S.: A new moist turbulence parameterization in the community atmosphere model, J. Climate, 22, 3422-3448, doi:10.1175/2008JCLI2556.1, 2009.

Cakmur, R. V., Miller, R. L., and Torres, O.: Incorporating the effect of small-scale circulations upon dust emission in an atmospheric general circulation model, J. Geophys. Res.-Atmos., 109, 7201, doi:10.1029/2003JD004067, 2004.

Capps, S. B. and Zender, C. S.: Observed and CAM3 GCM sea surface wind speed distributions: characterization, comparison, and bias reduction, J. Climate, 21, 6569, doi:10.1175/2008JCLI2374.1, 2008. 
Carta, J. A., Ramirez, P., and Velazquez, S.: A review of wind speed probability distributions used in wind energy analysis: case studies in the Canary Islands, Renew. Sust. Energ. Rev., 13, 933-955, doi:10.1016/j.rser.2008.05.005, 2009.

Deardorff, J. W.: Preliminary results from numerical integrations of the unstable planetary boundary layer, J. Atmos. Sci., 27, 1209-1210, doi:10.1175/15200469(1970)027<1209:PRFNIO>2.0.CO;2, 1970.

Dipankar, A., Stevens, B., Heinze, R., Moseley, C., Zängl, G., Giorgetta, M., and Brdar, S.: Large eddy simulation using the general circulation model ICON, J. Adv. Model. Earth Syst., 7, 963-986, doi:10.1002/2015MS000431, 2015.

Durran, D. R.: Mountain waves and downslope winds, in: Atmospheric Processes Over Complex Terrain, edited by: Blumen, W., vol. 23 of Meteorological Monographs, American Meteorological Society, Boston, Massachusetts, 59-83, 1990.

ECMWF: European Centre for Medium-Range Weather Forecasts (ECMWF): IFS Documentation - Cy28r1, IV. Physical Processes, Tech. Report, European Centre for Medium-Range Weather Forecasts, ECMWF Research Department, Technical Momorandum Cy28r1, European Centre for Medium-Range Weather Forecast, Reading, UK, available at: http://old.ecmwf. int/research/ifsdocs/CY28r1/index.html (last access: 24 August 2015), 2004.

Feng, Z., Hagos, S., Rowe, A. K., Burleyson, C. D., Martini, M. N., and de Szoeke, S. P.: Mechanisms of convective cloud organization by cold pools over tropical warm ocean during the AMIE/DYNAMO field campaign, J. Adv. Model. Earth Syst., 7, 357-381, doi:10.1002/2014MS000384, 2015.

Gettelman, A., Morrison, H., and Ghan, S. J.: A new twomoment bulk stratiform cloud microphysics scheme in the community atmosphere model, version 3 (CAM3). Part II: Single-column and global results, J. Climate, 21, 3660-3679, doi:10.1175/2008JCLI2116.1, 2008.

Ghan, S. J. and Easter, R. C.: Comments on "A limited-areamodel case study of the effects of sub-grid scale variations in relative humidity and cloud upon the direct radiative forcing of sulfate aerosol", Geophys. Res. Lett., 25, 1039-1040, doi:10.1029/98GL50357, 1998.

Gläser, G., Kerkweg, A., and Wernli, H.: The Mineral Dust Cycle in EMAC 2.40: sensitivity to the spectral resolution and the dust emission scheme, Atmos. Chem. Phys., 12, 1611-1627, doi:10.5194/acp-12-1611-2012, 2012.

Godfrey, J. S. and Beljaars, A. C. M.: On the turbulent fluxes of buoyancy, heat and moisture at the air-sea interface at low wind speeds, J. Geophys. Res., 96, 22043-22048, doi:10.1029/91JC02015, 1991.

Grini, A. and Zender, C. S.: Roles of saltation, sandblasting, and wind speed variability on mineral dust aerosol size distribution during the Puerto Rican Dust Experiment (PRIDE), J. Geophys. Res., 109, 7202, doi:10.1029/2003JD004233, 2004.

Gustafson, W. I., Qian, Y., and Fast, J. D.: Downscaling aerosols and the impact of neglected subgrid processes on direct aerosol radiative forcing for a representative global climate model grid spacing, J. Geophys. Res.-Atmos., 116, D13303, doi:10.1029/2010JD015480, 2011.

Haywood, J. M., Ramaswamy, V., and Donner, L. J.: A limitedarea-model case study of the effects of sub-grid scale variations in relative humidity and cloud upon the direct radiative forcing of sulfate aerosol, Geophys. Res. Lett., 24, 143-146, doi:10.1029/96GL03812, 1997.

Heinold, B., Tegen, I., Schepanski, K., and Banks, J. R.: New developments in the representation of Saharan dust sources in the aerosol-climate model ECHAM6-HAM2, Geosci. Model Dev. Discuss., 8, 7879-7910, doi:10.5194/gmdd-8-7879-2015, 2015.

Hourdin, F., Gueye, M., Diallo, B., Dufresne, J.-L., Escribano, J., Menut, L., Marticoréna, B., Siour, G., and Guichard, F.: Parameterization of convective transport in the boundary layer and its impact on the representation of the diurnal cycle of wind and dust emissions, Atmos. Chem. Phys., 15, 6775-6788, doi:10.5194/acp-15-6775-2015, 2015.

Huneeus, N., Schulz, M., Balkanski, Y., Griesfeller, J., Prospero, J., Kinne, S., Bauer, S., Boucher, O., Chin, M., Dentener, F., Diehl, T., Easter, R., Fillmore, D., Ghan, S., Ginoux, P., Grini, A., Horowitz, L., Koch, D., Krol, M. C., Landing, W., Liu, X., Mahowald, N., Miller, R., Morcrette, J.-J., Myhre, G., Penner, J., Perlwitz, J., Stier, P., Takemura, T., and Zender, C. S.: Global dust model intercomparison in AeroCom phase I, Atmos. Chem. Phys., 11, 7781-7816, doi:10.5194/acp-11-7781-2011, 2011.

Iacono, M. J., Delamere, J. S., Mlawer, E. J., Shephard, M. W., Clough, S. A., and Collins, W. D.: Radiative forcing by long-lived greenhouse gases: calculations with the AER radiative transfer models, J. Geophys. Res., 113, D13103, doi:10.1029/2008JD009944, 2008.

Jabouille, P., Redelsperger, J. L., and Lafore, J. P.: Modification of surface fluxes by atmospheric convection in the TOGA COARE region, Mon. Weather Rev., 124, 816-837, doi:10.1175/15200493(1996)124<0816:MOSFBA>2.0.CO;2, 1996.

Jeuken, A., Siegmund, P., Heijboer, L., Feichter, J., and Bengtsson, L.: On the potential of assimilating meteorological analyses in a global climate model for the purposes of model validation, J. Geophys. Res., 101, 16939-16950, doi:10.1029/96JD01218, 1996.

Justus, C. G., Hargraves, W. R., Mikhail, A., and Graber, D.: Methods for estimating wind speed frequency distributions, J. Appl. Meteorol., 17, 350-353, doi:10.1175/15200450(1978)017<0350:MFEWSF>2.0.CO;2, 1978.

Justus, C. G., Mani, K., and Mikhail, A. S.: Interannual and month-to-month variations of wind speed, J. Appl. Meteorol., 18, 913-920, doi:10.1175/15200450(1979)018<0913:IAMTMV>2.0.CO;2, 1979.

Kooperman, G. J., Pritchard, M. S., Ghan, S. J., Wang, M., Somerville, R. C. J., and Russell, L. M.: Constraining the influence of natural variability to improve estimates of global aerosol indirect effects in a nudged version of the Community Atmosphere Model 5, J. Geophys. Res., 117, D23204, doi:10.1029/2012JD018588, 2012.

Lawrence, D. M., Oleson, K. W., Flanner, M. G., Thornton, P. E., Swenson, S. C., Lawrence, P. J., Zeng, X., Yang, Z.-L., Levis, S., Sakaguchi, K., Bonan, G. B., and Slater, A. G.: Parameterization improvements and functional and structural advances in Version 4 of the Community Land Model, J. Adv. Model. Earth Syst., 3, M03001, doi:10.1029/2011MS000045, 2011.

Lin, S.-J.: A "Vertically Lagrangian" finite-volume dynamical core for global models, Mon. Weather Rev., 132, 2293-2307, doi:10.1175/1520-0493(2004)132<2293:AVLFDC>2.0.CO;2, 2004. 
Liu, X., Easter, R. C., Ghan, S. J., Zaveri, R., Rasch, P., Shi, X., Lamarque, J.-F., Gettelman, A., Morrison, H., Vitt, F., Conley, A., Park, S., Neale, R., Hannay, C., Ekman, A. M. L., Hess, P., Mahowald, N., Collins, W., Iacono, M. J., Bretherton, C. S., Flanner, M. G., and Mitchell, D.: Toward a minimal representation of aerosols in climate models: description and evaluation in the Community Atmosphere Model CAM5, Geosci. Model Dev., 5, 709-739, doi:10.5194/gmd-5-709-2012, 2012a.

Lumley, J. L. and Panofsky, H. A.: The Structure of Atmospheric Turbulence, Interscience Monographs and Texts in Physics and Astronomy, Interscience Publishers, New York, 239 pp., 1964.

Lunt, D. J. and Valdes, P. J.: The modern dust cycle: comparison of model results with observations and study of sensitivities, J. Geophys. Res., 107, 4669, doi:10.1029/2002JD002316, 2002.

Ma, P.-L., Rasch, P. J., Fast, J. D., Easter, R. C., Gustafson Jr., W. I., Liu, X., Ghan, S. J., and Singh, B.: Assessing the CAM5 physics suite in the WRF-Chem model: implementation, resolution sensitivity, and a first evaluation for a regional case study, Geosci. Model Dev., 7, 755-778, doi:10.5194/gmd-7-755-2014, 2014.

Mahoney, W. P.: Gust front characteristics and the kinematics associated with interacting thunderstorm outflows, Mon. Weather Rev., 116, 1474-1492, doi:10.1175/15200493(1988)116<1474:GFCATK>2.0.CO;2, 1988.

Marcella, M. P. and Eltahir, E. A. B.: Effects of mineral aerosols on the summertime climate of southwest Asia: incorporating subgrid variability in a dust emission scheme, J. Geophys. Res.Atmos., 115, 18203, doi:10.1029/2010JD014036, 2010.

Marsham, J. H., Knippertz, P., Dixon, N. S., Parker, D. J., and Lister, G. M. S., Geophys. Res. Lett., 38, L16803, doi:10.1029/2011GL048368, 2011.

Mårtensson, E. M., Nilsson, E. D., de Leeuw, G., Cohen, L. H., and Hansson, H.-C.: Laboratory simulations and parameterization of the primary marine aerosol production, J. Geophys. Res.-Atmos., 108, 4297, doi:10.1029/2002JD002263, 2003.

Menut, L.: Sensitivity of hourly Saharan dust emissions to NCEP and ECMWF modeled wind speed, J. Geophys. Res.-Atmos., 113, D16201, doi:10.1029/2007JD009522, 2008.

Mlawer, E. J., Taubman, S. J., Brown, P. D., Iacono, M. J., and Clough, S. A.: Radiative transfer for inhomogeneous atmospheres: RRTM, a validated correlated-k model for the longwave, J. Geophys. Res., 102, 16663-16682, doi:10.1029/97JD00237, 1997.

Monahan, A. H.: The probability distribution of sea surface wind speeds. Part II: Dataset intercomparison and seasonal variability, J. Climate, 19, 521, doi:10.1175/JCLI3641.1, 2006.

Morrison, H. and Gettelman, A.: A new two-moment bulk stratiform cloud microphysics scheme in the NCAR Community Atmosphere Model (CAM3), Part I: description and numerical tests, J. Climate, 21, 3642-3659, doi:10.1175/2008JCLI2105.1, 2008

Namikas, S. and Sherman, D. J.: Predicting Aeolian Sand Transport: Revisiting the White Model, Earth Surf. Proc. Landf., 22, 601604, doi:10.1002/(SICI)1096-9837(199706)22:6<601::AIDESP783>3.3.CO;2-X, 1997.

Neale, R. B., Chen, C. C., Gettelman, A., Lauritzen, P. H., Park, S., Williamson, D. L., Conley, A. J., Garcia, R., Kinnison, D., Lamarque, J. F., Marsh, D., Mills, M., Smith, A. K., Tilmes, S., Vitt, F., Morrison, H., Cameron-Smith, P., Collins, W. D., Iacono, M. J., Easter, R. C., Ghan, S. J., Liu, X. H., Rasch, P. J., and Taylor, M. A.: Description of the NCAR Community Atmosphere Model (CAM5.0), Tech. Rep. NCAR/TN-486STR, National Center for Atmospheric Research, Boulder, CO, USA, available at: http://www.cesm.ucar.edu/models/cesm1.0/ cam/ (last access: 24 August 2015), 2010.

Oleson, K., Lawrence, D., Bonan, G., Flanner, M., Kluzek, E. Lawrence, P., Levis, S., Swenson, S., Thornton, P., Dai, A., Decker, M., Dickinson, R., Feddema, J., Heald, C., Hoffman, F., Lamarque, J.-F., Mahowald, N., Niu, G.-Y., Qian, T., Randerson, J., Running, S., Sakaguchi, K., Slater, A., Stockli, R., Wang, A., Yang, Z.-L., Zeng, X., and Zeng, X.: Technical Description of version 4.0 of the Community Land Model (CLM), Tech. Rep. NCAR/TN-478+STR, National Center for Atmospheric Research, Boulder, CO, USA, available at: http: //www.cesm.ucar.edu/models/cesm1.0/clm/ (last access: $24 \mathrm{Au}-$ gust 2015), 2010.

Owen, P. R.: Saltation of uniform grains in air, J. Fluid Mech., 20, 225-242, doi:10.1017/S0022112064001173, 1964.

Panofsky, H., Tennekes, H., Lenschow, D., and Wyngaard, J.: The characteristics of turbulent velocity components in the surface layer under convective conditions, Bound.-Lay. Meteorol., 11, 355-361, doi:10.1007/BF02186086, 1977.

Park, S.: A unified convection scheme (UNICON). part I: formulation, J. Atmos. Sci., 71, 3902-3930, doi:10.1175/JAS-D-130234.1, 2014.

Park, S. and Bretherton, C. S.: The University of Washington shallow convection and moist turbulence schemes and their impact on climate simulations with the Community Atmosphere Model, J. Climate, 22, 3449-3469, doi:10.1175/2008JCLI2557.1, 2009.

Pavia, E. G. and O'Brien, J. J.: Weibull statistics of wind speed over the ocean., J. Appl. Meteorol., 25, 1324-1332, doi:10.1175/1520-0450(1986)025<1324:WSOWSO>2.0.CO;2, 1986.

Prospero, J. M., Ginoux, P., Torres, O., Nicholson, S. E., and Gill, T. E.: Environmental characterization of global sources of atmospheric soil dust identified with the NIMBUS 7 Total Ozone Mapping Spectrometer (TOMS) absorbing aerosol product, Rev. Geophys., 40, 1002, doi:10.1029/2000RG000095, 2002.

Qian, Y., Gustafson Jr., W. I., and Fast, J. D.: An investigation of the sub-grid variability of trace gases and aerosols for global climate modeling, Atmos. Chem. Phys., 10, 6917-6946, doi:10.5194/acp-10-6917-2010, 2010.

Redelsperger, J.-L., Guichard, F., and Mondon, S.: A parameterization of mesoscale enhancement of surface fluxes for large-scale models, J. Climate, 13, 402-421, doi:10.1175/15200442(2000)013<0402:APOMEO>2.0.CO;2, 2000

Ridley, D. A., Heald, C. L., Pierce, J. R., and Evans, M. J.: Toward resolution-independent dust emissions in global models: impacts on the seasonal and spatial distribution of dust, Geophys. Res. Lett., 40, 2873-2877, doi:10.1002/grl.50409, 2013.

Schepanski, K., Tegen, I., Laurent, B., Heinold, B., and Macke, A.: A new Saharan dust source activation frequency map derived from MSG-SEVIRI IR-channels, Geophys. Res. Lett., 34, 1944 8007, doi:10.1029/2007GL030168, 2007.

Schumann, U.: Minimum friction velocity and heat transfer in the rough surface layer of a convective boundary layer, Bound.-Lay. Meteorol., 44, 311-326, doi:10.1007/BF00123019, 1988. 
Skamarock, W. and Klemp, J.: A time-split nonhydrostatic atmospheric model for weather research and forecasting applications, J. Comput. Phys., 227, 3465-3485, doi:10.1016/j.jcp.2007.01.037, 2008.

Stevens, R. G. and Pierce, J. R.: A parameterization of subgrid particle formation in sulfur-rich plumes for global- and regional-scale models, Atmos. Chem. Phys., 13, 12117-12133, doi:10.5194/acp-13-12117-2013, 2013.

Textor, C., Schulz, M., Guibert, S., Kinne, S., Balkanski, Y., Bauer, S., Berntsen, T., Berglen, T., Boucher, O., Chin, M., Dentener, F., Diehl, T., Easter, R., Feichter, H., Fillmore, D., Ghan, S., Ginoux, P., Gong, S., Grini, A., Hendricks, J., Horowitz, L., Huang, P., Isaksen, I., Iversen, I., Kloster, S., Koch, D., Kirkevåg, A., Kristjansson, J. E., Krol, M., Lauer, A., Lamarque, J. F., Liu, X., Montanaro, V., Myhre, G., Penner, J., Pitari, G., Reddy, S., Seland, Ø., Stier, P., Takemura, T., and Tie, X.: Analysis and quantification of the diversities of aerosol life cycles within AeroCom, Atmos. Chem. Phys., 6, 1777-1813, doi:10.5194/acp-6-1777-2006, 2006.

Torres, O., Bhartia, P. K., Herman, J. R., Sinyuk, A., Ginoux, P., and Holben, B.: A long-term record of aerosol optical depth from TOMS observations and comparison to AERONET measurements, J. Atmos. Sci., 59, 398-413, doi:10.1175/15200469(2002)059<0398:ALTROA>2.0.CO;2, 2002.

Westphal, D. L., Toon, O. B., and Carlson, T. N.: A case study of mobilization and transport of Saharan dust, J. Atmos. Sci., 45, 2145-2175, doi:10.1175/15200469(1988)045<2145:ACSOMA>2.0.CO;2, 1988.

White, B.: Soil transport by winds on Mars, J. Geophys. Res., 84, 4643-4651, doi:10.1029/JB084iB09p04643, 1979.
Zender, C. S. and Kwon, E. Y.: Regional contrasts in dust emission responses to climate, J. Geophys. Res.-Atmos., 110, D13201, doi:10.1029/2004JD005501, 2005.

Zender, C. S., Bian, H., and Newman, D.: The mineral Dust Entrainment And Deposition (DEAD) model: description and 1990s dust climatology, J. Geophys. Res., 108, 4416, doi:10.1029/2002JD002775, 2003.

Zeng, X., Zhang, Q., Johnson, D., and Tao, W.-K.: Parameterization of wind gustiness for the computation of ocean surface fluxes at different spatial scales, Mon. Weather Rev., 130, 2125-2133, doi:10.1175/1520-0493(2002)130<2125:POWGFT>2.0.CO;2, 2002.

Zhang, G. J. and McFarlane, N. A.: Sensitivity of climate simulations to the parameterization of cumulus convection in the Canadian Climate Centre general circulation model, Atmos. Ocean, 33, 407-446, doi:10.1080/07055900.1995.9649539, 1995.

Zhang, K., O’Donnell, D., Kazil, J., Stier, P., Kinne, S., Lohmann, U., Ferrachat, S., Croft, B., Quaas, J., Wan, H., Rast, S., and Feichter, J.: The global aerosol-climate model ECHAM-HAM, version 2: sensitivity to improvements in process representations, Atmos. Chem. Phys., 12, 8911-8949, doi:10.5194/acp-12-89112012, 2012.

Zhang, K., Wan, H., Liu, X., Ghan, S. J., Kooperman, G. J., Ma, P.-L., Rasch, P. J., Neubauer, D., and Lohmann, U.: Technical Note: On the use of nudging for aerosol-climate model intercomparison studies, Atmos. Chem. Phys., 14, 8631-8645, doi:10.5194/acp-14-8631-2014, 2014. 